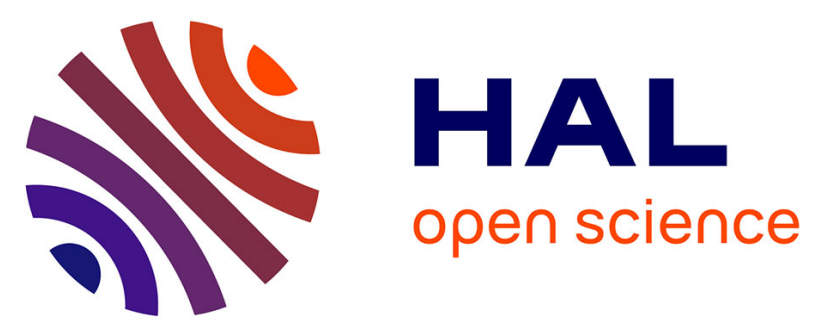

\title{
Asymmetric Allylic Alkylation of beta-Ketoesters via C-N Bond Cleavage of N-Allyl-N-methylaniline Derivatives Catalyzed by a Nickel-Diphosphine System
}

Haruki Nagae, Jingzhao Xia, Evgueni Kirillov, Kosuke Higashida, Koya Shoji, Valentin Boiteau, Wanbin Zhang, Jean-Francois Carpentier, Kazushi Mashima

\section{- To cite this version:}

Haruki Nagae, Jingzhao Xia, Evgueni Kirillov, Kosuke Higashida, Koya Shoji, et al.. Asymmetric Allylic Alkylation of beta-Ketoesters via C-N Bond Cleavage of N-Allyl-N-methylaniline Derivatives Catalyzed by a Nickel-Diphosphine System. ACS Catalysis, 2020, 10 (10), pp.5828-5839. 10.1021/acscatal.0c01356 . hal-02886396

\section{HAL Id: hal-02886396 https://hal.science/hal-02886396}

Submitted on 8 Jul 2020

HAL is a multi-disciplinary open access archive for the deposit and dissemination of scientific research documents, whether they are published or not. The documents may come from teaching and research institutions in France or abroad, or from public or private research centers.
L'archive ouverte pluridisciplinaire HAL, est destinée au dépôt et à la diffusion de documents scientifiques de niveau recherche, publiés ou non, émanant des établissements d'enseignement et de recherche français ou étrangers, des laboratoires publics ou privés. 


\title{
Asymmetric Allylic Alkylation of $\beta$-Ketoesters via $\mathrm{C}-\mathrm{N}$ Bond Cleavage of $N$-allyl- $N$-methylaniline Derivatives Catalyzed by a Nickel- Diphosphine System
}

\author{
Haruki Nagae, ${ }^{\dagger}$ Jingzhao Xia, ${ }^{\dagger,}{ }^{\ddagger}$ Evgueni Kirillov, ${ }^{\S}$ Kosuke Higashida, ${ }^{\dagger}$ Koya Shoji, ${ }^{\dagger}$ Valentin Boi- \\ teau, ${ }^{\dagger}$ Wanbin Zhang, ${ }^{*}{ }^{\ddagger}$ Jean-François Carpentier, ${ }^{*}{ }^{\S}$ and Kazushi Mashima*, ${ }^{\dagger}$ \\ ${ }^{\dagger}$ Graduate School of Engineering Science, Osaka University, Toyonaka, Osaka 560-8531, Japan \\ ‡ Shanghai Key Laboratory for Molecular Engineering of Chiral Drugs, School of Chemistry and Chemical Engineering \\ Shanghai Jiao Tong University, 800 Dongchuan Road, Shanghai 200240 (P. R. China) \\ ${ }^{\S}$ Institut des Sciences Chimiques de Rennes, Université Rennes, CNRS, ISCR, Université de Rennes 1, F-35042 Rennes \\ Cedex, France
}

KEYWORDS Asymmetric Allylic Alkylation • Nickel Catalyst $\bullet \beta$-Ketoesters $\bullet$ Allylic Amines $\bullet C-N$ Bond Cleavage

\begin{abstract}
Nickel complexes bearing chiral diphosphine ligands, such as ( $S$-Tol-MeO-BIPHEP and $(S)-\mathrm{H}_{8}$-BINAP, serve as efficient catalysts for asymmetric allylic alkylation (AAA) of $\beta$-ketoesters using allylic amines as allyl sources. The reactions proceed with high catalytic activity and high enantioselectivity. $N$-Methyl $-N$-phenyl allylic amines were indispensable to achieve the high catalytic activity and high enantioselectivity, and to expand the substrate scope to 5- and 7-membered $\beta$-ketoesters, whose nickel-catalyzed AAA with allylic alcohols results in low enantioselectivity. On the basis of the kinetics using a catalyst system made of $\mathrm{Ni}(\mathrm{cod})_{2}$ and $(S)$-Tol-MeO-BIPHEP, and DFT calculations for the reaction pathway of the AAA reaction mediated by an isolated olefin-coordinated nickel-DPPF complex $\mathbf{4 b}$, we propose a mechanism where protonation of the nitrogen atom of the coordinating allylic amine by $\beta$-ketoester is key to cleaving the $\mathrm{C}-\mathrm{N}$ bond and delivering a cationic $\pi$-allyl nickel(II) intermediate.
\end{abstract}

\section{Introduction}

Asymmetric allylic alkylation (AAA), the asymmetric version of transition metal-assisted nucleophilic substitution of allylic compounds, namely the Tsuji-Trost reaction, ${ }^{1,2}$ is one of the most efficient synthetic methods for producing optically active organic compounds. Allylic substrates bearing activated leaving groups such as carboxylates (acetates), ${ }^{3-5}$ carbonates, ${ }^{1 \mathrm{f}, 6-9}$ phosphates, ${ }^{10}$ and halides, ${ }^{11}$ as well as allylic molecules having trichloroacetimidate, ${ }^{12}$ trimethylsilyl, ${ }^{13}$ carbamates and ureas, ${ }^{14}$ exhibit high reactivity in AAA reactions. Nonetheless, allylic alcohols, ${ }^{1 \mathrm{~g}, 1 \mathrm{~h}, 15-18}$ ethers, ${ }^{1 \mathrm{~h}, 19}$ amines, ${ }^{1 \mathrm{~h}, 15 \mathrm{~h}, 20-23}$ and $\mathrm{C}-\mathrm{H}$ bond, ${ }^{24}$ were recently applied directly as simple alternative allylic sources, although AAA reaction with such stable allylic sources has been developed almost exclusively by using easyto-handle precious metal-based catalysts, such as palladium, rhodium, and iridium complexes. In this context, some of us recently reported the AAA reaction of $\beta$-ketoesters with allylic alcohols to construct quaternary chiral centers mediated by non-precious nickel complex bearing chiral diphosphine ligand. ${ }^{15 b}$ The substrate scope of the nickel-catalyzed AAA using allylic alcohols was quite narrow, however, and AAA was effective only when using 6-membered cyclic $\beta$-ketoesters: the use of 5- and 7-membered $\beta$-ketoesters afforded the corresponding products in quite low enantiomeric excess.

To further expand the scope of this nickel/chiral diphosphine system, we focused our attention on catalytic cleavage of the highly stable $\mathrm{C}-\mathrm{N}$ bond of allylic amines. ${ }^{20-23}$ The leaving ability of the amine moiety of allylic amines is finely controllable by changing substituents on the nitrogen atom, and we previously reported the palladium-catalyzed allylic alkylation of enamines with allylic amines. ${ }^{20}$ Scheme 1 shows some landmark AAA reactions using allylic amines catalyzed by palladium complexes. In 2007, List et al. reported the first catalytic AAA reaction using allylic amine as an allyl source, and $\mathrm{Pd}\left(\mathrm{PPh}_{3}\right)_{4}$ associated with a chiral phosphoric acid, $(R)$ TRIP, as a catalyst (Scheme 1a). ${ }^{21 a}$ One of us reported an AAA reaction using allylic amines and ketones catalyzed by $\left[\mathrm{Pd}\left(\eta^{3}-\mathrm{C}_{3} \mathrm{H}_{5}\right) \mathrm{Cl}\right]_{2}$ with a chiral ferrocene-based phosphinooxazoline ligand, in which $\mathrm{MeOH}$ acted as the best solvent because the $\mathrm{C}-\mathrm{N}$ bond of the allylic amines was activated by the hydrogen bond between the nitrogen atom of the allylic amine and the hydrogen atom of the methanol solvent (Scheme $1 \mathrm{~b}){ }^{20}$ Tian et al. achieved an AAA reaction of malononitriles with allylic amines, involving a kinetic resolution catalyzed by $\left[\mathrm{Pd}\left(\eta^{3}-\mathrm{C}_{3} \mathrm{H}_{5}\right) \mathrm{Cl}\right]_{2} /(S)$-BINAP (Scheme 1c). ${ }^{21 \mathrm{~b}}$ As shown in Scheme 1, AAA reactions with allylic amines were achieved by using precious palladium catalyst, and only one achiral allylation using allylic amine was accomplished by using nickel complex with achiral diphosphine ligand and metallic zinc as reductant. ${ }^{25}$ Herein, we report a highly effective nickel-catalyzed AAA reaction using allylic amines with a substrate scope not limited to 6 -membered $\beta$-ketoesters, but expanded to 5- and 7-membered benzo-fused $\beta$-ketoesters by further modification of the chiral diphosphine ligand (Scheme 
1d). This catalyst system expands the substrate scope of AAA reaction not only to allylic sources which have activated leaving groups but also to highly stable allylic amines.

Scheme 1. Examples of AAA Reactions Using Allylic Amines Assisted by Palladium-Based Catalysts ${ }^{20,21}$

a) B. List, et al. in 2007.

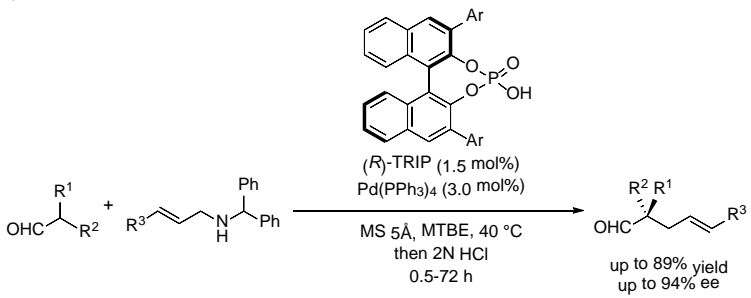

b) W. Zhang, et al. in 2011.

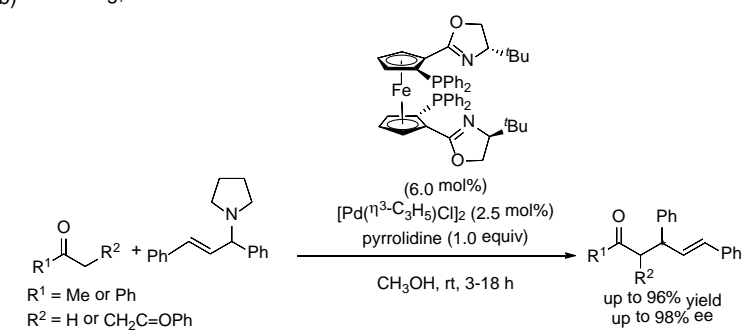

c) S. K. Tian, et al. in 2015 .

$$
\begin{gathered}
\begin{array}{c}
{\left[\mathrm{Pd}\left(\mathrm{\eta}^{3}-\mathrm{C}_{3} \mathrm{H}_{5}\right) \mathrm{Cl}\right] 2(1 \mathrm{~mol} \%)} \\
(\mathrm{S})-\mathrm{BINAP}(4 \mathrm{~mol})
\end{array} \\
\text { mesitylsulfonyl hydrazide (0.6 equiv) }
\end{gathered}
$$

d) This work

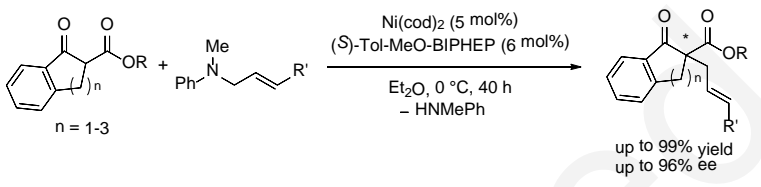

\section{Results and Discussion}

We began by searching for the best ligand among chiral diphosphines L1-8 (6 mol\%) in combination with $\mathrm{Ni}(\mathrm{cod})_{2}$ (5 mol\%) as a catalyst precursor for the AAA of $\beta$-ketoester 1a with allylic amine 2a chosen as the model substrate; representative results obtained in diethyl ether solution (see Table $\mathrm{S} 1$ for solvent screening results) at $0{ }^{\circ} \mathrm{C}$ for $40 \mathrm{~h}$ are summarized in Table 1 . The use of $(S)-\mathrm{H}_{8}-\mathrm{BINAP}(\mathbf{L 1})$, which is the best ligand in AAA of allylic alcohols, ${ }^{15 \mathrm{~b}}$ afforded product 3aa in $88 \%$ yield and $94 \%$ ee (entry 1 ). In the case of (S)-BINAP (L2), yield and enantioselectivity of 3aa were decreased to $74 \%$ and $91 \%$ ee, respectively (entry 2). Using (S)-TolBINAP (L3) and $(S)$-SEGPHOS (L4) yielded 3aa in quantitative yield with $92 \%$ ee and 94\% ee, respectively (entries 3 and $4)$. On the other hand, the sterically hindered (S)-DTBMSEGPHOS (L5) retarded the AAA reaction to give 3aa in only $12 \%$ yield with $14 \%$ ee (entry 5 ), while $(S)$-DIFLUORPHOS (L6) afforded 3aa in moderate yield with high enantioselectivity (entry 6). BIPHEP-type ligands, such as (S)-MeO-BIPHEP (L7) and (S)-Tol-MeO-BIPHEP (L8), were the most effective among the ligands investigated, giving 3aa in high yields (96\% and 99\%, respectively) and enantioselectivities (94\% ee and 95\% ee, respectively) (entries 7 and 8).
Table 1. Screening of Chiral Diphosphine Ligands
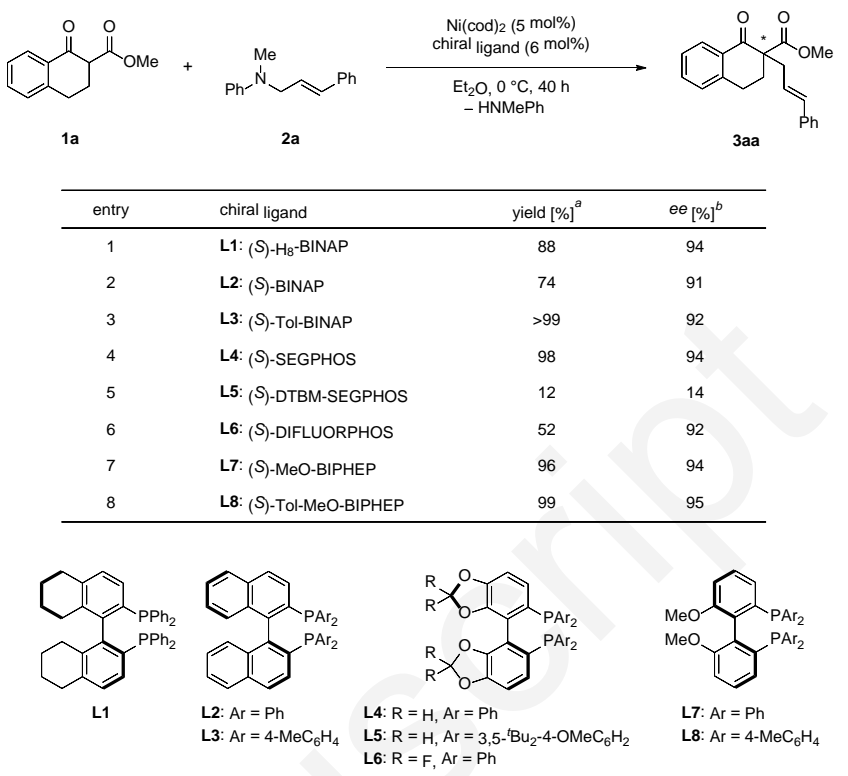

Reaction conditions: 1a $(0.50 \mathrm{mmol})$, 2a $(0.60 \mathrm{mmol}, 1.2$ equiv), $\mathrm{Ni}(\mathrm{cod})_{2}$ (5 mol\%), chiral diphosphine ligand (6 mol\%), and $\mathrm{Et}_{2} \mathrm{O}(1 \mathrm{~mL})$. ${ }^{\mathrm{a}}$ Determined by ${ }^{1} \mathrm{H}$ NMR analysis using triphenylmethane as an internal standard. ${ }^{b}$ Determined by HPLC analysis (see ESI).

We next examined the AAA reaction of various $N$ substituted allylic amine derivatives under typical conditions (5 mol\% of $\mathrm{Ni}(\mathrm{cod})_{2}, 6 \mathrm{~mol} \%$ of (S)-Tol-MeO-BIPHEP (L8), diethyl ether, $0^{\circ} \mathrm{C}, 40 \mathrm{~h}$ ) to evaluate the leaving ability of the amine moiety; the results are summarized in Table 2 . When $N$-cinnamyl- $N$-methylaniline (2a) was used, 3aa was obtained in $99 \%$ yield and with $95 \%$ ee (entry 1 ). On the other hand, $N, N$-diphenylamine $\mathbf{2 b}$ and $N$-phenylamine 2c derivatives resulted in lower yields of 3aa, $11 \%$ and $60 \%$, respectively, yet still with high enantioselectivities (entries 2 and 3). The use of $N$-cinnamylamine (2d) afforded 3aa but the yield, $8 \%$, and enantioselectivity, $61 \%$ ee, were lower than those obtained from 2a (entry 4 vs 1 ). Also, AAA reactions of $N$-cinnamyl$N, N$-dialkylamines, such as $N$-cinnamyl- $N, N$-dimethylamine (2e), $N$-cinnamyl- $N, N$-diethylamine (2f), and $N$-cinnamylpyrrolidine (2g) derivatives, afforded 3aa in low to moderate yields with moderate enantioselectivities (entries 5-7). Accordingly, we selected $N$-phenyl- $N$-methyl derivative 2a as the best substituent pattern for the allylic amine. We assumed that allylic amines having an electron-donating substituent accelerated the protonation of allylic amine and subsequent formation of a cationic nickel complex having a lower energy barrier to cleave the $\mathrm{C}-\mathrm{N}$ bond of allylic amine (vide infra). $\mathrm{N}$ Cinnamyl- $N, N$-dialkylamine derivatives exhibit high basicity, but the leaving-group ability of $N, N$-dialkylamines is lower than that of $N$-alkylaniline derivatives; this is consistent with the lower yields observed from $N, N$-dialkylallylamines, such as $\mathbf{2 d}$, $\mathbf{2 e}$, and $\mathbf{2 f}$, than from $N$-cinnamyl- $N$-methylaniline $\mathbf{2 a}$. Hence, there seems to exist a balance between the basicity and the leaving-group ability of the amine moiety of allylic amine to achieve high catalytic activity. 
Table 2. Screening of Substituents on Nitrogen Atom of Allylamines 2

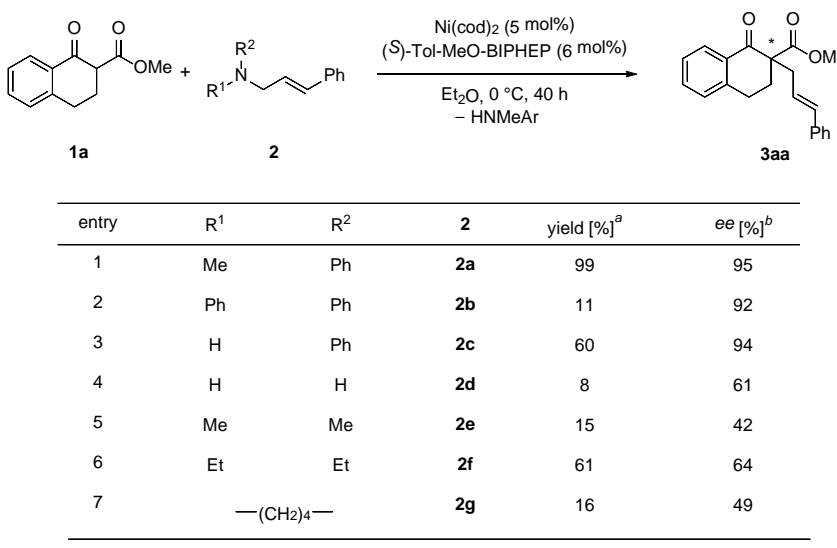

Reaction conditions: 1a $(0.50 \mathrm{mmol}), 2$ (0.60 mmol, 1.2 equiv), $\mathrm{Ni}(\mathrm{cod})_{2}$ (5 mol\%), $\mathbf{L 8}$ (6 mol\%), and $\mathrm{Et}_{2} \mathrm{O}(1 \mathrm{~mL})$. Determined by ${ }^{1} \mathrm{H}$ NMR analysis using triphenylmethane as an internal standard. ${ }^{b}$ Determined by HPLC analysis (see ESI).

With the optimized conditions in hands, we performed a large-scale reaction using $2.0 \mathrm{mmol}$ of $\mathbf{1 a}$ and $2.4 \mathrm{mmol}$ of $\mathbf{2 a}$; this eventually resulted in the corresponding product 3aa in 99\% yield and 95\% ee (eq. 1), although a slightly longer reaction time, $50 \mathrm{~h}$, was required to reach quantitative yield.
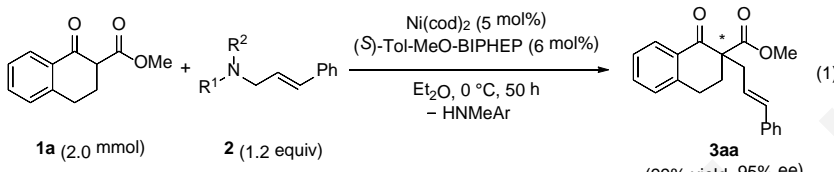

Under the optimized conditions using $N$-cinnamyl- $N$ methylaniline (2a), we evaluated the scope of nucleophilic substrates (Table 3). $\beta$-Ketoesters $\mathbf{1 b}$ and $\mathbf{1 c}$, which have a fused anisyl ring, reacted smoothly to afford the corresponding products 3ba and 3ca in high yields and excellent enantioselectivities (94\% ee and 96\% ee), respectively (entries 1 and 2). The use of dimethyl-substituted $\beta$-ketoester 1d yielded the corresponding product 3da in good yield with 93\% ee (entry $3)$. On the other hand, the AAA reaction of $\beta$-ketoester 1e having an ethyl ester was slow and required a longer reaction time, 80 h, to give 3ea in 99\% yield with 95\% ee; this suggests that the steric hindrance at the ester group directly affected the reactivity, but not the enantioselectivity (compare Table 2, entry 1 with Table 3 , entry 4). $\beta$-Ketoester 1f without an aromatic ring yielded product $\mathbf{3 f a}$ in moderate yield with high enantiomeric excess ( $96 \%$ ee) (entry 5). In contrast to the high enantioselectivities observed for $\beta$-ketoesters with a 6membered ring, contrivances by tuning the ligand and substrate substituents were required for 5-membered ring substrates. In fact, with the (S)-Tol-MeO-BIPHEP (L8)-based catalyst, $\beta$-ketoester $\mathbf{1 g}$ gave 3 ga in $99 \%$ yield, but with quite low enantioselectivity (21\% ee, entry 6). After reexamining the ligand system for the AAA reaction of $\beta$-ketoester having a 5-membered ring (Table S3), we selected (S)- $\mathrm{H}_{8}$-BINAP (L1) and obtained slightly better enantioselectivities (34\% ee at $0{ }^{\circ} \mathrm{C}$ for $40 \mathrm{~h}$ ) (entry 7). More importantly, when using ligand $\mathbf{L 1}$, we found that a bulky ester moiety improved both reactivity and enantioselectivity: hence, the reaction of $\beta$ ketoester $\mathbf{1 h}$ bearing the sterically hindered $\mathrm{COOCEt}_{3}$ ester group operated at temperatures as low as $0{ }^{\circ} \mathrm{C}$ and $-20{ }^{\circ} \mathrm{C}$ for $60 \mathrm{~h}$ and gave the corresponding AAA product 3ha in $99 \%$ yield with $82 \%$ ee and $88 \%$ ee, respectively (entries 8 and 9); operating at $-30{ }^{\circ} \mathrm{C}$ further increased the enantioselectivity to $92 \%$ ee, but the yield of the product dropped to 59\% (entry 10). The use of methyl and fluoro-substituted substrates 1i and $\mathbf{1 j}$ at $-20{ }^{\circ} \mathrm{C}$ for $60 \mathrm{~h}$ afforded the corresponding products 3ia and $3 \mathbf{j a}$ in quantitative yields with $82 \%$ ee and $90 \%$ ee, respectively (entries 11 and 12). Dimethoxy-substituted $\beta$ ketoester $\mathbf{1 k}$ gave $3 \mathbf{k a}$ in $74 \%$ yield and $79 \%$ ee (entry 13 ). A broader scope was demonstrated by using the 7-membered ring $\beta$-ketoester $\mathbf{1 l}$ using ligand $\mathbf{L 8}$ at $0{ }^{\circ} \mathrm{C}$, which resulted in $95 \%$ yield of 3la with $77 \%$ ee (entry 14$){ }^{26}$ We also investigated other nucleophiles such as $\beta$-diketone $\mathbf{1 m}, \beta$-ketoamide 1n, and $\beta$-diketonitrile $\mathbf{1 0}$. The use of $\mathbf{1 m}$ gave the corresponding product $3 \mathrm{ma}$ in $86 \%$ yield with low enantioselectivity (26\% ee), possibly due to the difference of coordination ability between the $-\mathrm{CO}_{2} \mathrm{Me}$ and $-\mathrm{C}(\mathrm{O}) \mathrm{Me}$ moieties (entry 15). When 1n was used as nucleophile, no reaction was observed, possibly because of the sterically hindered piperidine moiety and the higher $\mathrm{pKa}$ value of $\beta$-ketoamide than that of $\beta$-ketoester and $\beta$-diketone (entry 16). ${ }^{27}$ Interestingly, $\beta$ diketonitrile 10 reacted smoothly and afforded the corresponding product 3oa in 94\% yield with very high enantioselectivity (entry 17). It is unclear why the small nitrile group improved the selectivity but we assume this may also be related to the different coordination ability of the -CN moiety.

Next, we examined AAA of substituted allylic amines with an $N$-methyl aniline moiety, and the results are shown in Table 4. The steric hindrance on the aryl ring of cinnamyl moiety affected the reactivity: $p$ - and $m$-tolyl substituted allylic amines $\mathbf{2 h}$ and $\mathbf{2 i}$ afforded the corresponding products 3ah and 3ai in excellent yield with high enantioselectivity, respectively (entries 1 and 2), but the more sterically hindered $o$-tolyl substituted allylic amine $\mathbf{2} \mathbf{j}$ gave $\mathbf{3 a j}$ in slightly lower yield and enantiomeric excess ( $77 \%$ and $90 \%$ ee, entry 3$)$. More critical steric effects were observed when $\mathbf{2} \mathbf{k}$, which has a methyl group on 2-position of the cinnamyl moiety, was used as allyl source, as no reaction was observed (entry 4). Thus, the steric hindrance around the $\mathrm{C}=\mathrm{C}$ bond is quite essential. This is consistent with the $\mathrm{X}$-ray single crystal diffraction analysis of 4b which evidenced coordination of the $\mathrm{C}=\mathrm{C}$ bond to the nickel center, most likely as the first step of the AAA reaction (vide infra). $p$-Methoxy, and $p$-fluoro substituted allylic amines $\mathbf{2} \mathbf{l}$ and $\mathbf{2 m}$ afforded the corresponding products $3 \mathbf{a l}$ and 3am quantitatively with high enantioselectivity after $40 \mathrm{~h}$, respectively (entries 5-6). Allylic amine 2n, having a strong electron-withdrawing $p-\mathrm{CF}_{3}$ group, exhibited low reactivity to give 3an in $51 \%$ yield, but the high enantioselectivity was maintained (entry 7). By prolonging the reaction time to 120 $\mathrm{h}$, the corresponding product 3an was obtained in $87 \%$ yield with almost the same enantioselectivity (entry 8). $N$-Allyl- $N$ methylaniline (2o) and $N$-(2-buten-1-yl)aniline (2p) worked well and delivered products 3ao and 3ap in 99\% and 95\% yield after 40 h, respectively. Allylic amines $2 \mathbf{o}$ and $2 \mathbf{p}$ have less bulky substituents ( $\mathrm{H}$ and $\mathrm{Me}$, respectively) than $\mathrm{Ph}$ group, which decreased the enantioselectivity to $74 \%$ and $81 \%$ ee, respectively (entries 9 and 10). 
Table 3. $\beta$-Ketoesters Substrate Scope
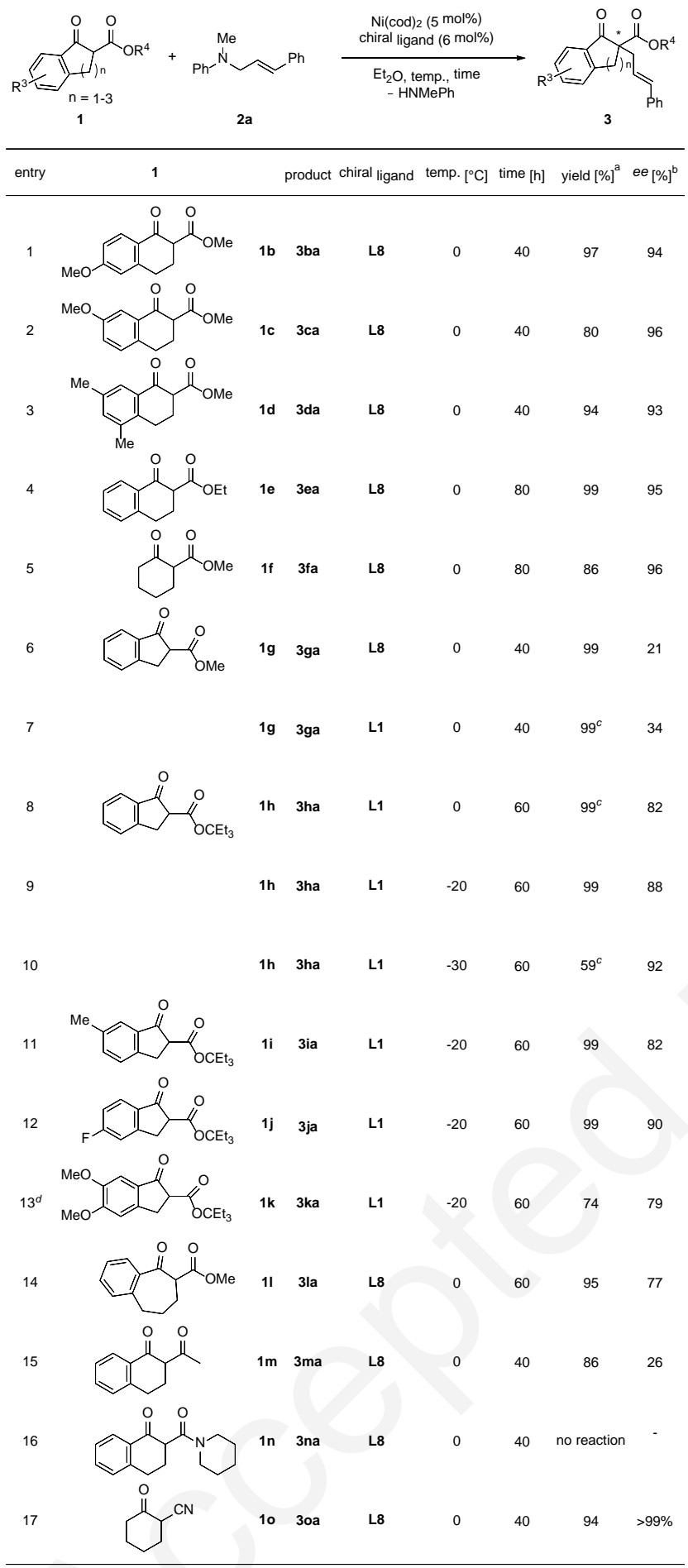

Reaction conditions: 1 (0.50 mmol), 2a (0.60 mmol, 1.2 equiv), $\mathrm{Ni}(\mathrm{cod})_{2}$ (5 mol\%), chiral diphosphine ligand (6 mol\%), and $\mathrm{Et}_{2} \mathrm{O}(1 \mathrm{~mL}) .{ }^{a}$ Isolated yield. ${ }^{b}$ Determined by HPLC analysis (see ESI). ${ }^{c}$ Determined by ${ }^{1} \mathrm{H}$ NMR analysis using triphenylmethane as an internal standard. ${ }^{d} 0.5 \mathrm{~mL}$ of toluene and $0.5 \mathrm{~mL}$ of $\mathrm{Et}_{2} \mathrm{O}$ were used as solvents due to the low solubility.

\section{Table 4. Allylic Amines Substrate Scope}

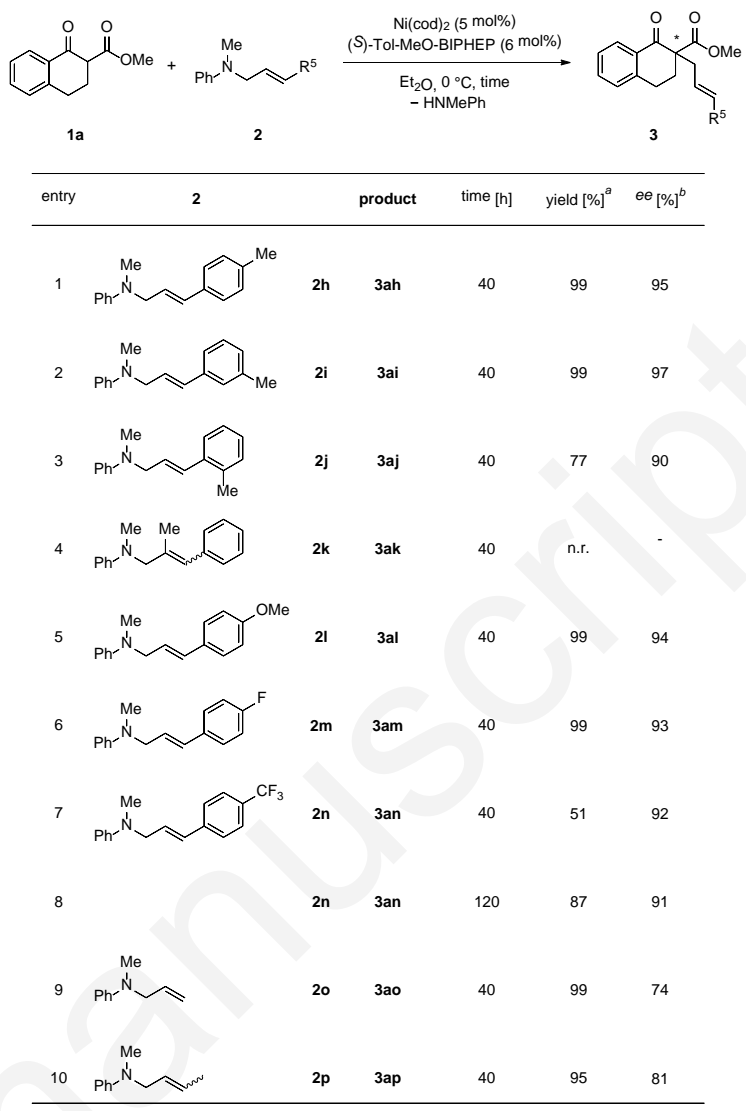

Reaction conditions: 1a (0.50 mmol), 2 (0.60 mmol, 1.2 equiv), $\mathrm{Ni}(\mathrm{cod})_{2}$ (5 mol\%), L8 (6 mol\%), and $\mathrm{Et}_{2} \mathrm{O}(1 \mathrm{~mL}){ }^{a}$ Isolated yield. ${ }^{b}$ Determined by HPLC analysis (see ESI).

To investigate the reaction mechanism, we prepared olefinic complexes $\mathbf{4 a}$ and $\mathbf{4 b}$ that, respectively, correspond to and mimic putative intermediates (Scheme 2). Complex 4a was prepared by treating (L8)Ni(cod) $(\mathbf{L 8}=(S)$-Tol-MeOBIPHEP) with allylic amine 2a. The ${ }^{31} \mathrm{P}\left\{{ }^{1} \mathrm{H}\right\}$ NMR spectrum of $\mathbf{4 a}$ in $\mathrm{C}_{6} \mathrm{D}_{6}$ displayed two equal-intensity doublets centered at $\delta 29.41$ and $24.20 \mathrm{ppm}$ with $J_{\mathrm{P}-\mathrm{P}}=47.4 \mathrm{~Hz}$ due to two nonequivalent phosphorus atoms of the chiral diphosphine ligand bound to $\mathrm{Ni}(0)$ center. In the ${ }^{1} \mathrm{H}$ NMR spectrum of $\mathbf{4 a}$, the allylic methylene hydrogens were observed at $\delta 3.5-3.3 \mathrm{ppm}$ as a multiplet signal, and two olefinic hydrogens were observed at $\delta 4.6-4.4 \mathrm{ppm}$ and $4.2-4.1 \mathrm{ppm}$ as multiplet signals. In addition, one olefinic carbon of 4 a was observed at $\delta 68.6$ ppm as a doublet of doublets $\left(J_{\mathrm{C}-\mathrm{P}}=16.7,2.0 \mathrm{~Hz}\right)$, and the other olefinic carbon of 4a was observed at $\delta 56.9-56.5 \mathrm{ppm}$ along with an olefinic carbon signal of COD of (L8) Ni(cod). Because all attempts to crystallize complex 4a failed to date, we isolated the related complex $\mathbf{4 b}$ in $23 \%$ yield as orange crystals from the reaction of $\mathrm{Ni}(\mathrm{cod})_{2}$ with $1,1^{\prime}$ bis(diphenylphosphino)ferrocene (DPPF) in the presence of an excess amount of 2a. Its structure was characterized by NMR spectroscopy and X-ray single-crystal analysis. Figure 1 shows the molecular structure of $\mathbf{4 b}$. The two phosphorus atoms of DPPF are bonded to the $\mathrm{Ni}(0)$ center with a $\mathrm{P} 1-\mathrm{Ni}-$ P2 bite angle of $106.84(3)^{\circ}$, which is almost the same as that $\left(107.13(9)^{\circ}\right)$ of $(\mathrm{DPPF}) \mathrm{Ni}^{0}\left(\mathrm{H}_{2} \mathrm{C}=\mathrm{CHCH}_{2} \mathrm{OH}\right){ }^{15 \mathrm{~b}}$ The C41$\mathrm{C} 42$ bond length of $1.417(4) \AA$ is consistent with other $\mathrm{C}=\mathrm{C}$ 
moieties coordinating to nickel( 0$)$ metal. ${ }^{15 b, 28}$ The sum of the bond angles around the nickel center, $\mathrm{P} 1-\mathrm{Ni}-\mathrm{P} 2, \mathrm{P} 2-\mathrm{Ni}-\mathrm{C}_{\text {cent }}$ $\left(\mathrm{C}_{\text {cent }}\right.$ is the centroid of $\mathrm{C} 41$ and $\mathrm{C} 42$ ), and $\mathrm{P} 1-\mathrm{Ni}-\mathrm{C}_{\text {cent }}$, is $359.2^{\circ}$, indicating an undistorted trigonal planar structure. The $\mathrm{Ni}$ “N1 distance (4.273(2) $\AA$ ) is beyond the interaction range.

Scheme 2. Synthesis of Olefinic Complexes 4a and 4b
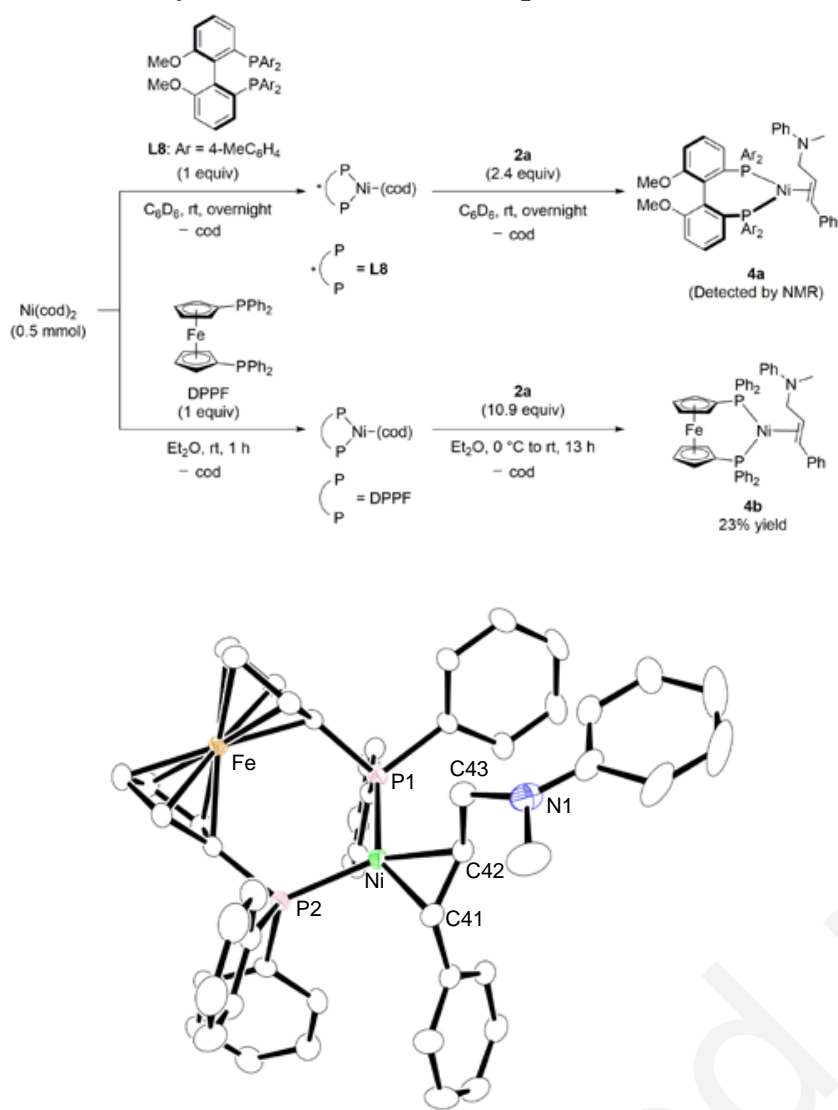

Figure 1. Molecular Structure of Complex 4 b with $50 \%$ Thermal Ellipsoids. All hydrogen atoms and solvent molecule are omitted for clarity. Selected bond distances $(\AA)$ and angles (deg): $\mathrm{Ni} \cdots \mathrm{Fe}, 4.0662(6)$; $\mathrm{Ni}-\mathrm{P} 1,2.1386(8) ; \mathrm{Ni}-\mathrm{P} 2$,

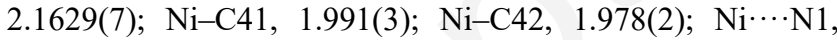
4.273(2); C41-C42, 1.417(4); C42-C43, 1.514(4); P1-Ni-P2, 106.84(3).

Although the steric characteristics of the isolated olefinDPPF complex $\mathbf{4 b}$ differ from those of complex $\mathbf{4 a},{ }^{29-31}$ which is the best catalyst identified but not isolable, we conducted control experiments with $\mathbf{4 b}$. Complex $\mathbf{4 b}$ and the in situ mixture of $\mathrm{Ni}(\mathrm{cod})_{2}$ and DPPF featured almost the same catalytic performance for the allylic alkylation reaction of 1a with 2a to afford 3aa (Scheme 3). In addition, we observed no reaction of (DPPF)Ni(cod) with $\beta$-ketoester 1a (eq. 2) and no oxidative addition of the $\mathrm{C}-\mathrm{N}$ bond of the coordinated allylic amine over complex $\mathbf{4 b}$ in $\mathrm{Et}_{2} \mathrm{O}$ at room temperature in the absence of substrate (eq. 3). These observations indicated that the coordination of $\mathbf{2 a}$ to '(DPPF)Ni' to form $\mathbf{4} \mathbf{b}$ proceeded smoothly as the first step of the reaction, but was not the ratedetermining step.
Scheme 3. Allylic Alkylation Reaction Catalyzed by The Isolated Complex $4 \mathrm{~b}$ and an in situ Mixture of $\mathrm{Ni}(\operatorname{cod})_{2}$ with DPPF

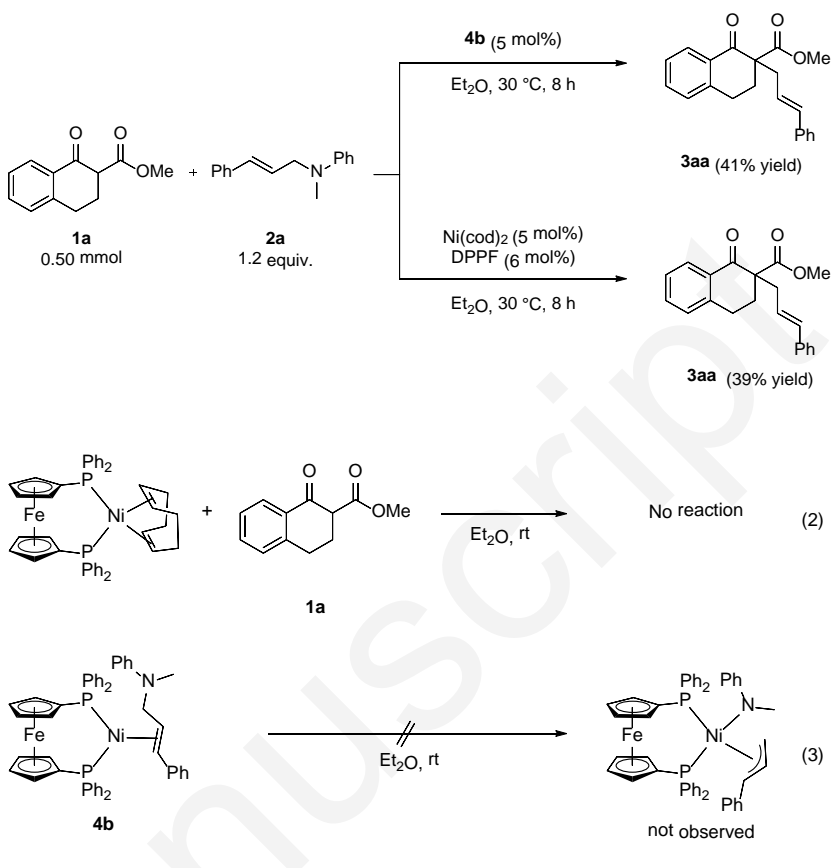

Kinetic monitoring of the AAA reaction of $\mathbf{1 a}$ and $\mathbf{2 a}$ was performed in $\mathrm{Et}_{2} \mathrm{O}$ using an in situ-generated catalyst system from $\mathrm{Ni}(\operatorname{cod})_{2}$ and $(S)$-Tol-MeO-Biphep (L8), because we could not use the isolated olefin-DPPF complex $\mathbf{4 b}$ due to its low solubility in $\mathrm{Et}_{2} \mathrm{O}$ at low temperature. At the initial stage, the reaction-rate constant was determined from the consumption rate of allylic amine 2a as monitored by ${ }^{1} \mathrm{H}$ NMR spectroscopic analysis with 1,3,5-trimethoxybenzene as an internal standard. The partial orders in the nickel catalyst ([Ni]), $\beta$ ketoester 1a ([1a]), and allylic amine 2a ([2a]) were determined using time normalization analysis (Figures S1-S3), ${ }^{32}$ and returned an experimental rate law $\propto[\mathrm{Ni}]^{0.5}[\mathbf{1 a}]^{1}[\mathbf{2 a}]^{1}$. The small rate dependency, less than 1 , on [Ni] suggests that free COD coordinates to nickel to form an inert ( $\mathbf{L 8}) \mathrm{Ni}(\mathrm{cod})$ species and prevents generation of the active complex $\mathbf{4 a}$, (L8) Ni(2a). ${ }^{33}$ In fact, we observed that the addition of 20 mol\% of COD to the reaction mixture remarkably decreased the AAA reaction rate (Figure S4). Based on the plot of $\ln \left(k_{\text {obs }} / T\right)$ versus $1 / T$ (Figure 2$)$, the activation parameters were determined: $\Delta H^{\ddagger}=12.8 \pm 2.5 \mathrm{kcal} \mathrm{mol}^{-1}, \Delta S^{\ddagger}=-142 \pm 36 \mathrm{~J} \mathrm{~K}^{-1}$ $\mathrm{mol}^{-1}$, and $\Delta G^{\ddagger}(298 \mathrm{~K})=22.8 \pm 5.1 \mathrm{kcal} \mathrm{mol}^{-1}$. The large negative $\Delta S^{\ddagger}$ value suggests a highly ordered transition state, and the low activation Gibbs free energy, 22.8 $\pm 5.1 \mathrm{kcal} \mathrm{mol}^{-1}$, was consistent with the result of the DFT calculation, $\Delta G^{\ddagger}(298 \mathrm{~K})$ $=26.4 \mathrm{kcal} \mathrm{mol}^{-1}$ (vide infra) although we employed a different diphosphine ligand, DPPF, instead of (S)-Tol-MeO-Biphep (L8) for DFT calculation. 
Figure 2. Eyring Plot for The AAA Reaction of 1a and 2a Performed in $\mathrm{Et}_{2} \mathrm{O}$ Using An in situ Generated Catalyst System From $\mathrm{Ni}(\mathrm{cod})_{2}$ and $(S)$-Tol-MeO-Biphep (L8)

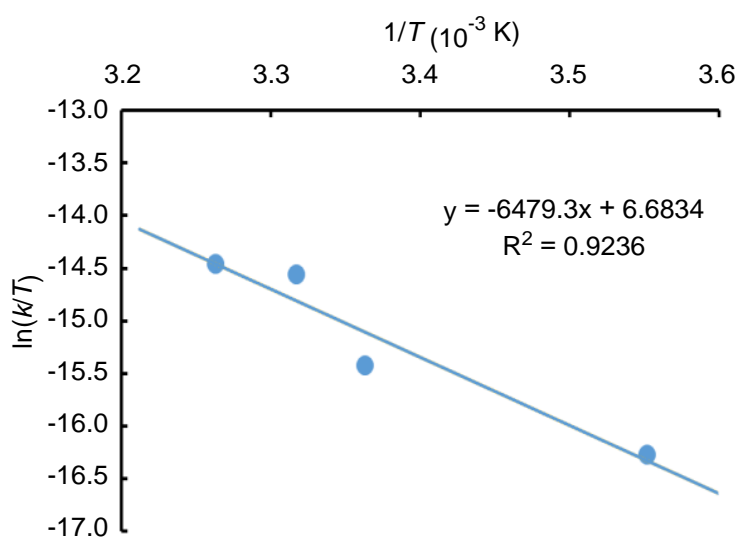

DFT calculations performed on the model Ni-DPPF system allowed us to rationalize a mechanism for AAA reactions catalyzed by the isolated olefin-Ni(0) complex $\mathbf{4 b}$ (Scheme 4 ), and key structures for some transition state are collected in Figure 3. After the first ligand exchange between one COD and DPPF to give (DPPF)Ni(cod) (Scheme 2), reaction of (DPPF)Ni(cod) with allylic amine 2a reversibly forms $\mathbf{4 b}$ which is stabilized by $6.6 \mathrm{kcal} \mathrm{mol}^{-1}$. Protonation of the amine moiety of $\mathbf{4 b}$ by $\beta$-ketoester $\mathbf{1 f}$ proceeds endergonically by $22.9 \mathrm{kcal} \mathrm{mol}^{-1}$ to generate intermediate $\mathbf{A}$ and enolate $\mathbf{1 f}$. Electron-withdrawing groups on the nitrogen atom of allylic amine increase the energy gap between $\mathbf{4 b}$ with $\mathbf{1 f}$ and $\mathbf{A}$ with $\mathbf{1 f}$, which decreases the rate of the protonation step $(\mathbf{4 b} \rightarrow \mathbf{A})$.
Cleavage of the $\mathrm{C}-\mathrm{N}$ bond of $\mathbf{A}$ affords cationic nickel $\pi$-allyl complex B via transition state TS1 cat $^{\text {outer }}$ along with release of $N$-methylaniline. The energy barrier $\mathbf{4 b} \rightarrow$ TS1cat $^{\text {outer }}$ is $26.4 \mathrm{kcal} \mathrm{mol}^{-1}$, a much lower value than that of the estimated energy barrier of the alternative pathway $\left(\mathbf{A}^{\prime} \rightarrow \mathbf{T S 1} \rightarrow \mathbf{B}^{\prime}\right.$, 33.6 $\mathrm{kcal} \mathrm{mol}^{-1}$ ) where a neutral nickel allyl complex B' (i.e., without preliminary protonation) is generated via oxidative addition of the $\mathrm{C}-\mathrm{N}$ bond. It is a reliable pathway by which the cationic complex $\mathbf{B}$ reacts with enolate $\mathbf{1 f}^{-}$to give an enolate adduct B-1f and neutral nickel alkyl species D. Complex B reacts with an outer-sphere enolate $\mathbf{1 f}^{-}$to give an olefin complex $\mathbf{C}$ including a quaternary carbon at the $\alpha$-position of the carbonyl moiety via stable transition state $\mathbf{T S} 2^{\text {outer }}$. The activation barrier of the outer-sphere pathway (24.1 $\mathrm{kcal} \mathrm{mol}^{-1}$ ), involving the $\mathbf{B} \leftrightarrow \mathbf{D}$ pre-equilibrium step through a low-lying $\mathbf{T S}_{\mathrm{B}-\mathrm{D}}$, is slightly lower than $\mathrm{C}-\mathrm{N}$ bond cleavage step. We excluded another possible pathway in which complex $\mathbf{D}$ reacts with inner-sphere enolate to give complex $\mathbf{C}$ via $\mathbf{T S} 2^{\text {inner }}$ due to its much higher energy barrier (34.9 $\mathrm{kcal} \mathrm{mol}^{-1}$ ) than TS2 $^{\text {outer }}{ }^{34}$ Finally, an exchange reaction of complex $\mathbf{C}$ by allylic amine $\mathbf{2 a}$ affords the corresponding intermediate $\mathbf{4 b}$. On the basis of kinetic data showing first-order rate dependence on [2a], the $\mathrm{C}-\mathrm{C}$ bond formation step $\left(\mathbf{D} \rightarrow \mathbf{T S} \mathbf{2}^{\text {outer }} \rightarrow \mathbf{C}\right)$ is suggested to be the rate-determining step; of note, the corresponding calculated activation barrier is slightly lower than that of $\mathbf{4 b} \rightarrow$ TS1 cat $^{\text {outer }} \rightarrow \mathbf{B}$ (24.1 vs. $26.4 \mathrm{kcal} \mathrm{mol}^{-1}$, respectively) but this slight difference $\left(2.3 \mathrm{kcal} \cdot \mathrm{mol}^{-1}\right)$ falls within the error of the DFT method. ${ }^{35}$

\section{Scheme 4. DFT-Computed Reaction Pathways of Nickel-Catalyzed AAA Reaction of $\beta$-Ketoesters with Allylic Amines}

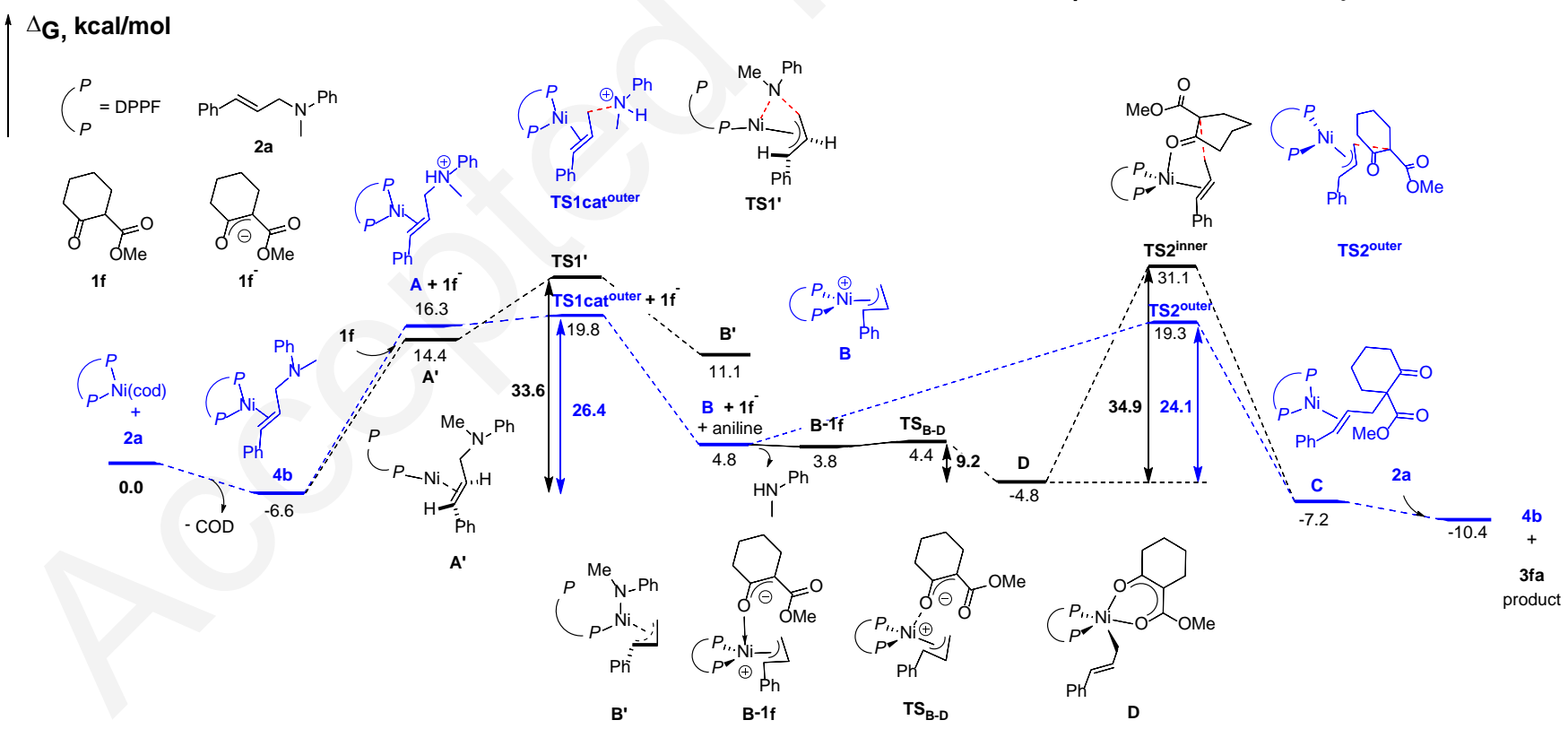


(a)

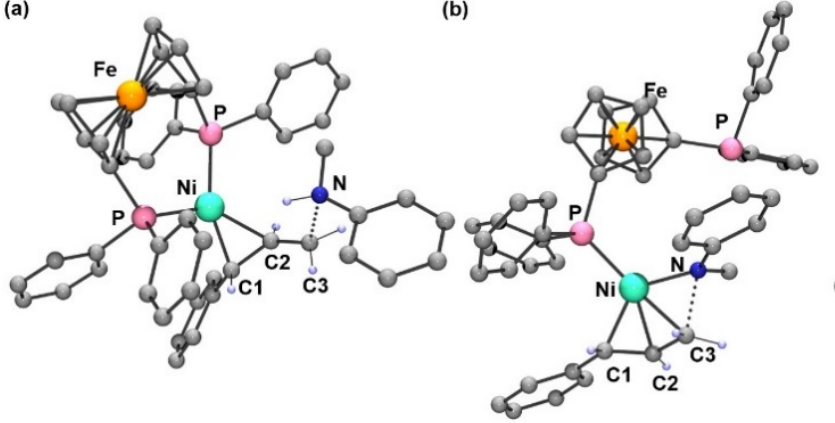

(c)

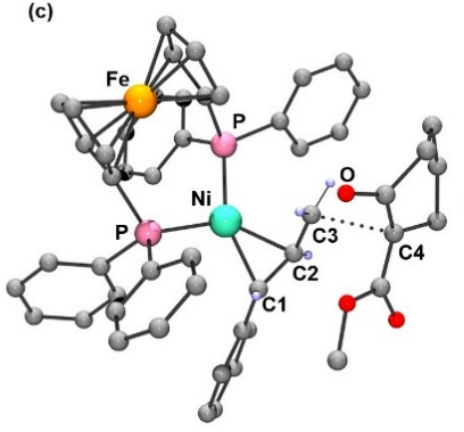

(d)

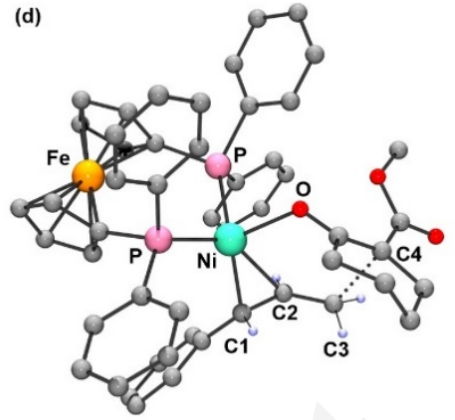

Figure 3. Calculated Structures of (a) TS1 cat ${ }^{\text {outer }}$, (b) TS1', (c) TS2 ${ }^{\text {outer }}$, (d) TS2 ${ }^{\text {inner }}$. Hydrogen atoms on Ph and Cp ring, Me, and $\beta$-ketoester are omitted for clarity.

Based on these control experiments and DFT calculations, we propose a catalytic cycle of the AAA reaction mediated by $\mathrm{Ni}(0)$ species, as shown in Scheme 5. In the nickel-catalyzed AAA reaction, the first step is coordination of allylic amine 2 onto the $\mathrm{Ni}(0)$-diphosphine complex to form olefin complex 4 . The amine moiety of complex $\mathbf{4}$ is then protonated by $\beta$ ketoester $\mathbf{1}$ to give cationic olefin complex $\mathbf{A}$ and enolate $\mathbf{1}$. Cleavage of the $\mathrm{C}-\mathrm{N}$ bond of $\mathbf{A}$ affords $\mathbf{B}$ via transition state TS1, as the rate-determining step. Then, an outer-sphere enolate anions $\mathbf{1}^{-}$reacts with $\mathbf{B}$ to form olefin complex $\mathbf{C}$ with a quaternary carbon at the $\alpha$-position of the carbonyl moiety. Lastly, an olefin exchange reaction between $\mathbf{C}$ and $\mathbf{2}$ proceeds to give the corresponding product $\mathbf{3}$ and regenerates catalytic intermediate 4

It is noteworthy to compare the current nickel catalyst system with the palladium catalyst system derived from $\left[\operatorname{Pd}\left(\eta^{3}\right.\right.$ $\left.\left.\mathrm{C}_{3} \mathrm{H}_{5}\right) \mathrm{Cl}\right]_{2}$ and a chiral ferrocene-based phosphinooxazoline ligand. ${ }^{20}$ In the latter system, activation of the allylic amine is proposed to proceed by protonation from methanol used as a solvent; yet, the use of methanol as solvent in our nickel system decreased the conversion of $\mathbf{1 a}$ and $\mathbf{2 a}$ to afford only $8 \%$ yield of 3aa (ie, $92 \%$ of $\mathbf{1 a}$ and $\mathbf{2 a}$ left) with $30 \%$ ee (Table S1).

Scheme 5. Proposed Reaction Mechanism for The NickelDiphosphine-Catalyzed AAA Reaction Using Allylic Amine and $\beta$-Ketoester

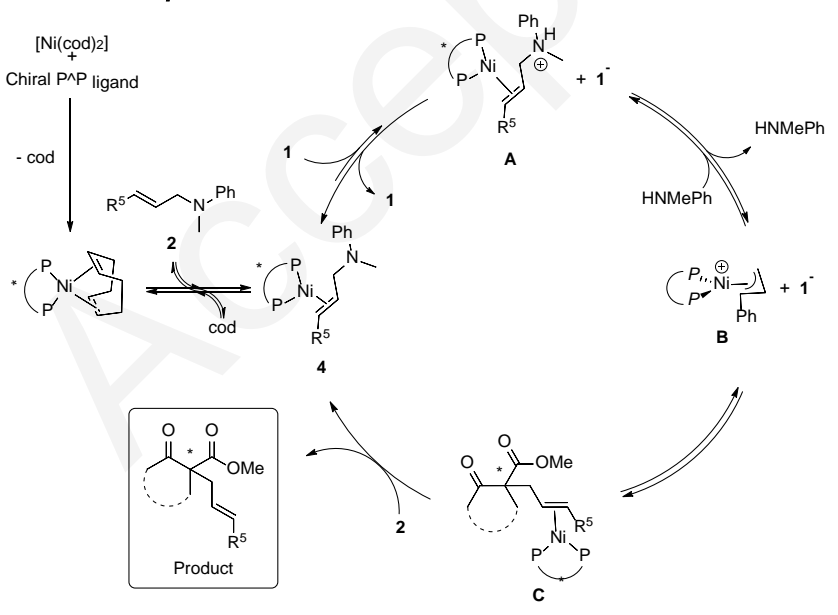

\section{Conclusion}

We developed an efficient version of the AAA reaction with a catalyst system made of cheap and readily available $\mathrm{Ni}(0)$ and a chiral diphosphine ligand using allylic amines as the allyl source. Some stoichiometric reactions as well as DFT calculations revealed the reaction mechanism, in which deprotonation of $\beta$-ketoesters by the $N$-methylaniline moiety of allylic amines is the key step to smoothly cleave the $\mathrm{C}-\mathrm{N}$ bond. The $\mathrm{C}-\mathrm{N}$ bond cleavage pathway of this nickel-catalyzed AAA reaction is completely different from that of palladiumcatalyzed systems. Although our $\mathrm{Ni}(0)$ system is sensitive to the choice of chiral diphosphine ligands, the demonstrated scope of effective AAA reactions is broad. Related AAA reactions using other allyl sources and substrates such as enamines are on-going projects in our laboratory

\section{Experimental Section}

General: All reactions and manipulations involving air- and moisture-sensitive organometallic compounds were operated using the standard Schlenk or dry box techniques under argon atmosphere. $\mathrm{MeOH}$ was dried and deoxygenated by distillation over sodium benzophenone ketyl under argon. Benzonitrile was distilled from the calcium hydride. Super dehydrated DMF was purchased from Wako Pure Chemical Industries, Ltd. and used as received. Alternatively, $\mathrm{Et}_{2} \mathrm{O}$, acetonitrile, THF, toluene and $\mathrm{CH}_{2} \mathrm{Cl}_{2}$ were dried and deoxygenated by using Grubbs column (Glass Counter Solvent Dispending System, Nikko Hansen \& Co, Ltd.). ${ }^{36}$ Other chemicals were purchased and used without further purification. ${ }^{1} \mathrm{H}$ NMR (400 MHz), ${ }^{13} \mathrm{C}\left\{{ }^{1} \mathrm{H}\right\}$ NMR (100 MHz) and ${ }^{19} \mathrm{~F}\left\{{ }^{1} \mathrm{H}\right\}$ NMR (376 MHz) spectra were measured on Bruker Avance III-400 spectrometers. All ${ }^{1} \mathrm{H}$ NMR chemical shifts were reported in ppm $(\delta)$ relative to tetramethylsilane at $\delta 0.00 \mathrm{ppm}$ or referenced to the chemical shifts of residual solvent resonances (THF- $d_{8}$ was used as internal standard, $\delta 3.57 \mathrm{ppm}$ ). All ${ }^{13} \mathrm{C}\left\{{ }^{1} \mathrm{H}\right\}$ NMR chemical shifts were reported in ppm $(\delta)$ relative to carbon resonances of $\mathrm{CDCl}_{3}$ at $\delta 77.16 \mathrm{ppm}$, or $\alpha$ carbon of THF- $d_{8}$ at $\delta 67.21 \mathrm{ppm}$. All ${ }^{19} \mathrm{~F}\left\{{ }^{1} \mathrm{H}\right\}$ NMR chemical shifts were reported in ppm $(\delta)$ relative to carbon resonances in $\alpha, \alpha, \alpha$-trifluorotoluene at $\delta-63.90 \mathrm{ppm}$. HPLC spectra were recorded on a JASCO UV-2075. Optical rotation values were recorded on an Anton Paar MCP100 polarimeter at $589 \mathrm{~nm}$ (sodium lamp) and are given in $10^{-1} \mathrm{deg} \mathrm{cm}^{2} \mathrm{~g}^{-1}$. Mass spectra were obtained on JEOL JMS-700. All melting points were recorded on BUCHI Melting Point M-565. All Infrared spectroscopy were recorded on Jasco FT/IR-4200. Flash column chromatography was performed using silica gel 60 (0.040$0.0663 \mathrm{~nm}, 230-400$ mesh ASTM). X-ray crystal data were 
collected with a Rigaku RAXIS-RAPID Imaging Plate diffractometer. The elemental analyses were recorded by using Perkin Elmer 2400 at the Faculty of Engineering Science, Osaka University.

General procedure for $\mathrm{Ni}$-catalyzed AAA reaction of $\boldsymbol{\beta}$ ketoesters with allylamines: $\mathrm{Ni}(\mathrm{cod})_{2}(0.025 \mathrm{mmol}, 5.0$ mol\%), Diphosphine ligand (0.030 mmol, $6.0 \mathrm{~mol} \%)$, and $\beta$ ketoester $(0.50 \mathrm{mmol}$, in the case of solid compounds) were added to a $20 \mathrm{~mL}$ Schlenk flask in an argon filled glove box. Then, dry $\mathrm{Et}_{2} \mathrm{O}(1.0 \mathrm{~mL})$ and $\beta$-ketoester $(0.50 \mathrm{mmol}$, in the case of liquid compounds) were added to the reaction mixture under argon. After $10 \mathrm{~min}$, the allylic amine $(0.60 \mathrm{mmol}, 1.2$ equiv) was added to the reaction mixture under argon atmosphere at $-30-0{ }^{\circ} \mathrm{C}$. The reaction mixture was stirred at $0{ }^{\circ} \mathrm{C}$. After consumption of $\beta$-ketoester, as monitored by TLC, the reaction mixture was quenched with ethyl acetate $(40 \mathrm{~mL})$ followed by washing with $6 \mathrm{~N}$ hydrochloric acid $(20 \mathrm{~mL} \times 2)$ and saturated aqueous solution of $\mathrm{NaHCO}_{3}(30 \mathrm{~mL})$. The organic layer was dried over $\mathrm{Na}_{2} \mathrm{SO}_{4}$. The filtrate was concentrated in vacuo, and the residue was purified by flash column chromatography on silica gel to afford the corresponding AAA product.

\section{Computational studies}

General Considerations: The calculations were performed using the Gaussian $09^{37}$ program employing B3PW91 ${ }^{38}$ functional, and using a standard double- $\xi$ polarized basis set, namely the LANL2DZ set, augmented with a single polarization $f$ function on iron and nickel (2.462 and 3.130, respectively) and a single polarization $d$ function on phosphorous (0.364). The solvent effects, in our case for $\mathrm{Et}_{2} \mathrm{O}$, were taken into account during all the calculations by means of the SMD model. $^{39}$ All stationary points were fully characterized via analytical frequency calculations as either true minima (all positive eigenvalues) or transition states (one imaginary eigenvalue). The IRC procedure was used to confirm the nature of each transition state connecting two minima. ${ }^{40}$ Zero-point vibrational energy corrections (ZPVE) were estimated by a frequency calculation at the same level of theory, to be considered for the calculation of the total energy values.

\section{ASSOCIATED CONTENT}

\section{Supporting Information}

Details of experimental procedures, optimization of reaction conditions, kinetic studies, NMR spectra, HPLC chart for all new compounds, and Cartesian coordinates of DFT-computed structures (PDF) were included in a Supporting Information. X-ray crystallographic data for complex $\mathbf{4 b}$ (CIF).

\section{AUTHOR INFORMATION}

\section{Corresponding Authors}

Prof. Dr. Kazushi Mashima - Graduate School of Engineering Science, Osaka University, Toyonaka, Osaka 560-8531, Japan

Email:mashima@chem.es.osaka-u.ac.jp

Prof. Dr. Jean-François Carpentier - Institut des Sciences Chimiques de Rennes, Univ. Rennes, CNRS, ISCR, Université de Rennes 1, F-35042 Rennes Cedex, France Email: jean-francois.carpentier@univ-rennes1.fr
Prof. Dr. Wanbin Zhang - Shanghai Key Laboratory for Molecular Engineering of Chiral Drugs, School of Chemistry and Chemical Engineering Shanghai Jiao Tong University, 800 Dongchuan Road, Shanghai 200240 (P. R. China) Email: wanbin@sjtu.edu.cn

\section{Authors}

Dr. Haruki Nagae - Graduate School of Engineering Science, Osaka University, Toyonaka, Osaka 560-8531, Japan

Dr. Jingzhao Xia - Graduate School of Engineering Science, Osaka University, Toyonaka, Osaka 560-8531, Japan, and Shanghai Key Laboratory for Molecular Engineering of Chiral Drugs, School of Chemistry and Chemical Engineering Shanghai Jiao Tong University, 800 Dongchuan Road, Shanghai 200240 (P. R. China)

Dr. Evgueni Kirillov - Institut des Sciences Chimiques de Rennes, Université Rennes, CNRS, ISCR, Université de Rennes 1, F-35042 Rennes Cedex, France

Dr. Kosuke Higashida - Graduate School of Engineering Science, Osaka University, Toyonaka, Osaka 560-8531, Japan

Mr. Koya Shoji - Graduate School of Engineering Science, Osaka University, Toyonaka, Osaka 560-8531, Japan

Mr. Valentin Boiteau - Graduate School of Engineering Science, Osaka University, Toyonaka, Osaka 560-8531, Japan

\section{ACKNOWLEDGMENT}

This work was supported by JSPS KAKENHI Grant Numbers JP15H05808 and JP15K21707 in Precisely Designed Catalysts with Customized Scaffolding (No. 2702) and National Natural Science Foundation of China (No. 21620102003). V. B., an internship student from INP-ENSIACET, thanks the INPENSIACET for financial support. We appreciate to Prof. Dr. Sensuke Ogoshi for his fruitful discussion. E.K. is grateful to ENSCR for computational facilities.

\section{REFERENCES}

(1) Reviews for AAA reactions: a) Trost, B. M.; Van Vranken, D. L. Asymmetric Transition Metal-Catalyzed Allylic Alkylations. Chem. Rev. 1996, 96, 395-422. b) Trost, B. M.; Crawley, M. L. Asymmetric Transition-Metal-Catalyzed Allylic Alkylations: Applications in Total Synthesis. Chem. Rev. 2003, 103, 2921-2944. c) Trost, B. M. Asymmetric Allylic Alkylation, An Enabling Methodology. J. Org. Chem. 2004, 69, 5813-5837. d) Trost, B. M.; Machacek, M. R.; Aponick, A. Predicting the Stereochemistry of Diphenylphosphino Benzoic Acid (DPPBA)-Based Palladium-Catalyzed Asymmetric Allylic Alkylation Reactions: A Working Model. Acc. Chem. Res. 2006, 39, 747-760. e) Lu, Z.; Ma, S. Metal-Catalyzed Enantioselective Allylation in Asymmetric Synthesis. Angew. Chem., Int. Ed. 2008, 47, 258-297. f) Weaver, J. D.; Recio, A.; Grenning, A. J.; Tunge, J. A. Transition Metal-Catalyzed Decarboxylative Allylation and Benzylation Reactions. Chem. Rev. 2011, 111, 1846-1913. g) Sundararaju, B.; Achard, M.; Bruneau, C. Transition Metal Catalyzed Nucleophilic Allylic Substitution: Activation of Allylic Alcohols via m-Allylic Species. Chem. Soc. Rev. 2012, 41, 4467-4483. h) Butt, N. A.; Zhang, W. Transition MetalCatalyzed Allylic Substitution Reactions with Unactivated Allylic Substrates. Chem. Soc. Rev. 2015, 44, 7929-7967. i) Quintavalla, A.; Bandini, M. Gold-Catalyzed Allylation Reactions. ChemCatChem 2016, 8, 1437-1453. j) Butt, N.; Yang, G.; Zhang, W. Allylic Alkylations with Enamine Nucleophiles. Chem. Rec. 2016, 16, 2683-2692. k) Hethcox, J. C.; Shockley, S. E.; Stoltz, B. M. Iridium-Catalyzed Diastereo-, Enantio-, and Regioselective Allylic Alkylation with Prochiral 
Enolates. ACS Catal. 2016, 6, 6207-6213. I) Fu, J.; Huo, X.; Li, B.; Zhang, W. Cooperative Bimetallic Catalysis in Asymmetric Allylic Substitution. Org. Biomol. Chem. 2017, 15, 9747-9759. m) Shockley, S. E.; Hethcox, J. C.; Stoltz, B. M. Intermolecular Stereoselective IridiumCatalyzed Allylic Alkylation: An Evolutionary Account. Synlett 2018, 29, 2481-2492.

(2) Some highlight articles for AAA reaction: a) Yorimitsu, H.; Oshima, K. Recent Progress in Asymmetric Allylic Substitutions Catalyzed by Chiral Copper Complexes. Angew. Chem., Int. Ed. 2005, 44, 4435-4439. b) You, S. L.; Dai, L. X. Enantioselective Palladium-Catalyzed Decarboxylative Allylic Alkylations. Angew. Chem., Int. Ed. 2006, 45, 52465248. c) Braun, M.; Meier, T. Tsuji-Trost Allylic Alkylation with Ketone Enolates. Angew. Chem., Int. Ed. 2006, 45, 6952-6955.

(3) Asymmetric $\mathrm{C}-\mathrm{C}$ bond formation reactions using allylic carboxylates, previous reports are in references 1: a) Xia, C.; Shen, J.; Liu, D.; Zhang, W. Synthesis of Chiral $\alpha, \beta$-Unsaturated $\gamma$-Amino Esters via PdCatalyzed Asymmetric Allylic Amination. Org. Lett. 2017, 19, 42514254. b) An, Q.; Liu, D.; Shen, J.; Liu, Y.; Zhang, W. The Construction of Chiral Fused Azabicycles Using a Pd-Catalyzed Allylic Substitution Cascade and Asymmetric Desymmetrization Strategy. Org. Lett. 2017, 19, 238-241. c) Panda, S.; Ready, J. M. Palladium Catalyzed Asymmetric Three-Component Coupling of Boronic Esters, Indoles, and AlIylic Acetates. J. Am. Chem. Soc. 2017, 139, 6038-6041. d) Huo, X.; He, R.; Fu, J.; Zhang, J.; Yang, G.; Zhang, W. Stereoselective and Site-Specific Allylic Alkylation of Amino Acids and Small Peptides via a Pd/Cu Dual Catalysis. J. Am. Chem. Soc. 2017, 139, 9819-9822. e) Borràs, C.; Elías-Rodríguez, P.; Carmona, A. T.; Robina, I.; Pàmies, O.; Diéguez, M. Amino-P Ligands from Iminosugars: New Readily Available and Modular Ligands for Enantioselective Pd-Catalyzed AlIylic Substitutions. Organometallics 2018, 37, 1682-1694. f) Shockley, S. E.; Hethcox, J. C.; Stoltz, B. M. Asymmetric synthesis of all-carbon quaternary spirocycles via a catalytic enantioselective allylic alkylation strategy. Tetrahedron Lett. 2017, 58, 3341-3343. g) Alexy, E. J.; Virgil S. C.; Bartberger, M. D.; Stoltz, B. M. Enantioselective Pd-Catalyzed Decarboxylative Allylic Alkylation of Thiopyranones. Access to Acyclic, Stereogenic a-Quaternary Ketones. Org. Lett. 2017, 19, 5007-5009. h) Lu, Y.; Goldstein, E. L.; Stoltz, B. M. Palladium-Catalyzed Enantioselective $\mathrm{C}_{\mathrm{sp} 3}-\mathrm{C}_{\mathrm{sp} 3}$ Cross-Coupling for the Synthesis of (Poly)fluorinated Chiral Building Blocks. Org. Lett. 2018, 20, 56575660. i) Sun, A. W.; Hess, S. N.; Stoltz, B. M. Enantioselective Synthesis of gem-disubstituted N-Boc diazaheterocycles via decarboxylative asymmetric allylic alkylation. Chem. Sci. 2019, 10, 788-792. j) Yao, L.; Nie, H.; Zhang, D.; Wang, L.; Zhang, Y.; Chen, W.; Li, Z.; Liu, X.; Zhang, S. Chiral Ferrocenyl $N, N$ Ligands with Intramolecular Hydrogen Bonds for Highly Enantioselective Allylic Alkylations. ChemCatChem 2018, 10, 804-809. k) Song, T.; Arseniyadis, S.; Cossy, J. Highly Enantioselective, Base - Free Synthesis of a-Quaternary Succinimides through Catalytic Asymmetric Allylic Alkylation. Chem. Eur. J. 2018, 24, 8076-8080. I) Liao, G.; Li, B.; Chen, H. M.; Yao, Q. J.; Xia Y. N.; Luo, J.; Shi, B. F. Pd-Catalyzed Atroposelective C-H Allylation through $\beta-O$ Elimination: Diverse Synthesis of Axially Chiral Biaryls. Angew. Chem., Int. Ed. 2018, 57, 17151-17155. m) He, R.; Wu, S.; Tang, H.; Huo, X.; Sun, Z.; Zhang, W. Iridium-Catalyzed Enantioselective and Diastereoselective Allylation of Dioxindoles: A One-Step Synthesis of 3-Allyl-3-hydroxyoxindoles. Org. Lett. 2018, 20, 6183-6187. n) Huo, X.; Fu, J.; He, X.; Chen, J.; Xie, F.; Zhang, W. Pd/Cu Dual Catalysis: Highly Enantioselective Access to $\alpha$-Substituted $\alpha$-Amino Acids and $\alpha$-Amino Amides. Chem. Commun. 2018, 54, 599-602. o) Biosca, M.; Margalef, J.; Caldentey, X.; Besora, M.; Rodríguez-Escrich, C.; Saltó, J.; Cambeiro, X. C.; Maseras, F.; Pàmies, O.; Diéguez, M.; Pericàs, M. A. Computationally Guided Design of a Readily Assembled Phosphite-Thioether Ligand for a Broad Range of Pd-Catalyzed Asymmetric Allylic Substitutions. ACS Catal. 2018, 8, 3587-3601.

(4) $\mathrm{C}-\mathrm{C}$ bond formation reactions using allylic carboxylates, previous reports are in references 1: a) Ghorpade, S. A.; Sawant, D. N.; Renn, D.; Zernickel, A.; Du, W.; Sekar, N.; Eppinger, J. Aqueous Protocol for Allylic arylation of Cinnamyl Acetates with Sodium Tetraphenylborate Using a Bedford-Type Palladacycle Catalyst. New J. Chem. 2018, 42, 6210-6214. b) Ghorpade, S. A.; Sawant, D. N.; Makki, A.; Sekar, N.;
Eppinger, J. Water Promoted Allylic Nucleophilic Substitution Reactions of $(E)-1,3$ Diphenylallyl Acetate. Green Chem. 2018, 20, 425430.

(5) Asymmetric $\mathrm{C}-\mathrm{N}$ bond formation reactions using allylic carboxylates, previous reports are in references 1: Lu, B.; Feng, B.; Ye, H.; Chen, J. R.; Xiao, W. J. Pd/Phosphoramidite Thioether Complex-Catalyzed Asymmetric N-Allylic Alkylation of Hydrazones with Allylic Acetates. Org. Lett. 2018, 20, 3473-3476.

(6) Asymmetric $\mathrm{C}-\mathrm{C}$ bond formation reactions using allylic carbonates, previous reports are in references 1: a) Wei, X.; Liu, D.; An, Q.; Zhang, W. Hydrogen-Bond Directed Regioselective Pd-Catalyzed Asymmetric Allylic Alkylation: The Construction of Chiral $\alpha$-Amino Acids with Vicinal Tertiary and Quaternary Stereocenters. Org. Lett. 2015, 17, 57685771; b) Yao, K.; Liu, D.; Yuan, Q.; Imamoto, T.; Liu, Y.; Zhang, W. 1,3-Dithianes as Acyl Anion Equivalents in Pd-Catalyzed Asymmetric Allylic Substitution. Org. Lett. 2016, 18, 6296-6299. c) Huo, X.; He, R.; Zhang, X.; Zhang, W. An Ir/Zn Dual Catalysis for Enantio-and Diastereodivergent $\alpha$-Allylation of $\alpha$-Hydroxyketones. J. Am. Chem. Soc. 2016, 138, 11093-11096. d) He, R.; Liu, P.; Huo, X.; Zhang, W. Ir/Zn Dual Catalysis: Enantioselective and Diastereodivergent $\alpha$-Allylation of Unprotected $\alpha$-Hydroxy Indanones. Org. Lett. 2017, 19, 5513-5516. e) Wei, L.; Xu, S. M.; Zhu, Q.; Che, C.; Wang, C. J. Synergistic Cu/Pd Catalysis for Enantioselective Allylic Alkylation of Aldimine Esters: Access to $\alpha, \alpha$-Disubstituted $\alpha$-Amino Acids. Angew. Chem., Int. Ed. 2017, 56, 12312-12316. f) Pritchett, B. P.; Donckele, E. J.; Stoltz, B. M. Enantioselective Catalysis Coupled with Stereodivergent Cyclization Strategies Enables Rapid Syntheses of (+)-Limaspermidine and (+)-Kopsihainanine A. Angew. Chem., Int. Ed. 2017, 56 (41), 1262412627. g) Jiang, X.; Boehm, P.; Hartwig, J. F. Stereodivergent Allylation of Azaaryl Acetamides and Acetates by Synergistic Iridium and Copper Catalysis. J. Am. Chem. Soc. 2018, 140, 1239-1242. h) Wei, L.; Zhu, Q.; Xu, S. M.; Chang, X.; Wang, C. J. Stereodivergent Synthesis of $\alpha, \alpha$-Disubstituted $\alpha$-Amino Acids via Synergistic Cu/Ir Catalysis. J. Am. Chem. Soc. 2018, 140, 1508-1513. i) Huo, X.; Zhang, J.; Fu, J.; He, R.; Zhang, W. Ir/Cu Dual Catalysis: Enantio- and Diastereodivergent Access to $\alpha, \alpha$-Disubstituted $\alpha$-Amino Acids Bearing Vicinal Stereocenters. J. Am. Chem. Soc. 2018,140, 2080-2084. j) Alexy, E. J.; Zhang, H.; Stoltz, B. M. Catalytic Enantioselective Synthesis of Acyclic Quaternary Centers: Palladium-Catalyzed Decarboxylative Allylic Alkylation of Fully Substituted Acyclic Enol Carbonates. J. Am. Chem. Soc. 2018, 140, 10109-10112. k) Trost, B. M.; Bai, Y.; Bai, W. J.; Schultz, J. E. Enantioselective Divergent Synthesis of C19-Oxo Eburnane Alkaloids via Palladium-Catalyzed Asymmetric Allylic Alkylation of an N-Alkyl- $\alpha, \beta$-unsaturated Lactam. J. Am. Chem. Soc. 2019, 141, 4811-4814. I) Chen, L. H.; Ma, Y. T.; Yang, F.; Huang, X. Y.; Chen, S. W.; Ji, K.; Chen, Z. S. Chemo - Selective Rh(II)/Pd(0) Dual Catalysis: Synthesis of All - Carbon $\mathrm{C}_{3}$ - Quaternary Allylic Oxindoles from $N$-Aryl- $\alpha$-Diazo- $\beta$-Keto-Amides with Functionalized Allyl Carbonates. Adv. Synth. Catal. 2019, 1307-1312. m) Sun, M.; Chen, J. F.; Chen, S.; Li, C. Construction of Vicinal Quaternary Carbon Centers via Cobalt-Catalyzed Asymmetric Reverse Prenylation. Org. Lett. 2019, 21, 1278-1282.

(7) $\mathrm{C}-\mathrm{C}$ bond formation reactions using allylic carbonates, previous reports are in references 1: a) Motokura, K.; Ikeda, M.; Nambo, M.; Chun, W. J.; Nakajima, K.; Tanaka, S. Concerted Catalysis in Tight Spaces: Palladium-Catalyzed Allylation Reactions Accelerated by Accumulated Active Sites in Mesoporous Silica. ChemCatChem 2017, 9 , 2924-2929. b) van Gemmeren, M.; Börjesson, M.; Tortajada, A.; Sun, S. Z.; Okura, K.; Martin, R. Switchable Site-Selective Catalytic Carboxylation of Allylic Alcohols with $\mathrm{CO}_{2}$. Angew. Chem., Int. Ed. 2017, 56, 6558-6562. c) Guo, W.; Kuniyil, R.; Gómez, J. E.; Maseras, F.; Kleij, A. W. A Domino Process toward Functionally Dense Quaternary Carbons through Pd-Catalyzed Decarboxylative $\mathrm{C}\left(\mathrm{sp}^{3}\right)-\mathrm{C}\left(\mathrm{sp}^{3}\right)$ Bond Formation. J. Am. Chem. Soc. 2018, 140, 3981-3987. d) Zhan, M.; Pu, X.; He, B.; Niu, D.; Zhang, X. Intramolecular Umpolung Allylation of Imines. Org. Lett. 2018, 20, 5857-5860.

(8) Asymmetric $\mathrm{C}-\mathrm{N}$ bond formation reactions using allylic carbonates, previous reports are in references 1: Zhou, Y.; Breit, B. RhodiumCatalyzed Asymmetric N-H Functionalization of Quinazolinones with 
Allenes and Allylic Carbonates: The First Enantioselective Formal Total Synthesis of (-)-Chaetominine. Chem. Eur. J. 2017, 23, 1815618160.

(9) $\mathrm{C}-\mathrm{N}$ bond formation reactions using allylic carbonates, previous reports are in references 1: a) Guo, W.; Martínez-Rodríguez, L.; Kuniyil, R.; Martin, E.; Escudero-Adán, E. C.; Maseras, F.; Kleij, A. W. Stereoselective and Versatile Preparation of Tri-and Tetrasubstituted AlIylic Amine Scaffolds under Mild Conditions. J. Am. Chem. Soc. 2016 138, 11970-11978. b) Isobe, S.; Terasaki, S.; Hanakawa, T.; Mizuno, S.; Kawatsura, M. Ruthenium-Catalyzed Regioselective Allylic Amination of 2,3,3-Trifluoroallylic Carbonates. Org. Biomol. Chem. 2017, 15, 2938-2946. c) Yang, Y.; Yang, W. Divergent Synthesis of $\mathrm{N}$ heterocycles by $\mathrm{Pd}$-Catalyzed Controllable Cyclization of Vinylethylene Carbonates. Chem. Commun. 2018, 54, 12182-12185. d) Deng, L.; Kleij, A. W.; Yang, W. Diversity-Orientated Stereoselective Synthesis through $\mathrm{Pd}-$ Catalyzed Switchable Decarboxylative C-N/C-S Bond Formation in Allylic Surrogates. Chem. Eur. J. 2018, 24, 1915619161.

(10) Asymmetric $\mathrm{C}-\mathrm{C}$ bond formation reactions using allylic phosphates, previous reports are in references 1: a) Han, J. T.; Jang, W. J.; Kim, N.; Yun, J. Asymmetric Synthesis of Borylalkanes via CopperCatalyzed Enantioselective Hydroallylation. J. Am. Chem. Soc. 2016, 138, 15146-15149. b) Xu, G.; Zhao, H.; Fu, B.; Cang, A.; Zhang, G.; Zhang, Q.; Xiong, T.; Zhang, Q. Ligand-Controlled Regiodivergent and Enantioselective Copper-Catalyzed Hydroallylation of Alkynes. Angew. Chem., Int. Ed. 2017, 56, 13130-13134. c) Kim, N.; Han, J. T.; Ryu, D. H.; Yun, J. Copper-Catalyzed Asymmetric Borylallylation of Vinyl Arenes. Org. Lett. 2017, 19, 6144-6147.

(11) Chiral and achiral $\mathrm{C}-\mathrm{C}$ bond formation reactions using allylic halides, previous reports are in references 1: a) Schäfer, P.; Sidera, M.; Palacin, T.; Fletcher, S. P. Asymmetric Cross-Coupling of Alkyl, Alkenyl and (Hetero) Aryl Nucleophiles with Racemic Allyl Halides. Chem. Commun. 2017, 53, 12499-12511. b) Yang, Z. P.; Jiang, R.; Zheng, C.; You, S. L. Iridium-Catalyzed Intramolecular Asymmetric Allylic Alkylation of Hydroxyquinolines: Simultaneous Weakening of the Aromaticity of Two Consecutive Aromatic Rings. J. Am. Chem. Soc. 2018, 140, 3114-3119. c) Yang, X.; Tsui, G. C. Copper-Mediated Trifluoromethylation-Allylation of Arynes. Org. Lett. 2018, 20, 1179-1182. d) Matsui, J. K.; Gutiérrez-Bonet, Á.; Rotella, M.; Alam, R.; Gutierrez, O.; Molander, G. A. Photoredox/Nickel-Catalyzed Single-Electron TsujiTrost Reaction: Development and Mechanistic Insights. Angew. Chem., Int. Ed. 2018, 57, 15847-15851.

(12) $\mathrm{C}-\mathrm{N}$ bond formation reactions using allylic molecule having trichloroacetimidate moiety; Shimizu, M.; Kikuchi, J.; Kondoh, A.; Terada, M. Chiral Brønsted Acid-Catalyzed Intramolecular $\mathrm{S}_{\underline{N}} \underline{2}$ ' Reaction for Enantioselective Construction of A Quaternary Stereogenic Center. Chem. Sci. 2018, 9, 5747-5757.

(13) Kaib, P. S. J.; Schreyer, L.; Lee, S.; Properzi, R.; List, B. Extremely Active Organocatalysts Enable a Highly Enantioselective Addition of Allyltrimethylsilane to Aldehydes. Angew. Chem., Int. Ed. 2016, 55, 13200-13203.

(14) $\mathrm{C}-\mathrm{N}$ bond formation reaction using allylic carbamates and ureas; Abrams, R.; Lefebvre, Q.; Clayden, J. Transition Metal Free Cycloamination of Prenyl Carbamates and Ureas Promoted by Aryldiazonium Salts. Angew. Chem., Int. Ed. 2018, 57, 13587-13591.

(15) Asymmetric $\mathrm{C}-\mathrm{C}$ bond formation reactions using allylic alcohols, previous reports are in references 1: a) Huo, X.; Yang, G.; Liu D.; Liu, Y.; Gridnev, I. D.; Zhang, W. Palladium-Catalyzed Allylic Alkylation of Simple Ketones with Allylic Alcohols and Its Mechanistic Study. Angew. Chem., Int. Ed. 2014, 53, 6776-6780. b) Kita, Y.; Kavthe, R. D.; Oda, H.; Mashima, K. Asymmetric Allylic Alkylation of $\beta$-Ketoesters with Allylic Alcohols by a Nickel/Diphosphine Catalyst. Angew. Chem., Int. Ed. 2016, 55, 1098-1101. c) Pupo, G.; Properzi, R.; List, B. Asymmetric Catalysis with $\mathrm{CO}_{2}$ : The Direct $\alpha$-Allylation of Ketones. Angew. Chem., Int. Ed. 2016, 55, 6099-6102. d) Shen, D.; Chen, Q.; Yan, P.; Zeng, X.; Zhong, G. Enantioselective Dearomatization of Naphthol Derivatives with Allylic Alcohols by Cooperative Iridium and Brønsted Acid Catalysis. Angew. Chem., Int. Ed. 2017, 56, 3242-3246. e) Yoshida, M. Asymmetric $\alpha$-Allylation of $\alpha$-Substituted $\beta$-Ketoesters with Allyl Alcohols. J. Org. Chem. 2017, 82, 12821-12826. f) Tang, S. B.; Zhang, X.; Tu, H. F.; You, S. L. Regio- and Enantioselective Rhodium-Catalyzed Allylic Alkylation of Racemic Allylic Alcohols with 1,3Diketones. J. Am. Chem. Soc. 2018, 140, 7737-7742. g) Liu, J.; Mishra, S.; Aponick, A. Catalytic Enantioselective Synthesis of Acyclic Quaternary Centers: Palladium-Catalyzed Decarboxylative Allylic Alkylation of Fully Substituted Acyclic Enol Carbonates. J. Am. Chem. Soc. 2018, 140, 16152-16158. h) Sweeney, J. B.; Ball, A. K.; Smith, L. J. Catalytic C-C Bond Formation Using a Simple Nickel Precatalyst System: Base- and Activator-Free Direct C-Allylation by Alcohols and Amines. Chem. Eur. J. 2018, 24, 7354-7357.

(16) C $-\mathrm{C}$ bond formation reactions using allylic alcohols, previous reports are in references 1: a) Shibuya, R.; Lin, L.; Nakahara, Y.; Mashima, K.; Ohshima, T. Dual Platinum and Pyrrolidine Catalysis in the Direct Alkylation of Allylic Alcohols: Selective Synthesis of Monoallylation Products. Angew. Chem., Int. Ed. 2014, 53, 4377-4381. b) Goodwin, J. A.; Ballesteros, C. F.; Aponick, A. Diastereoselective Synthesis of Protected 1,3-Diols by Catalytic Diol Relocation. Org. Lett. 2015, 17, 5574-5577; c) Blieck, R.; Azizi, M. S.; Mifleur, A.; Roger, M.; Persyn, C.; Sauthier, M.; Bonin, H. Nickel-Catalysed Bis-Allylation of Activated Nucleophiles with Allyl Alcohol. Eur. J. Org. Chem. 2016, 2016, 11941198. d) Abidi, A.; Oueslati, Y.; Rezgui, F. Beilstein Et $\underline{t}_{3}$ B-Mediated and Palladium-Catalyzed Direct Allylation of $\beta$-Dicarbonyl Compounds with Morita-Baylis-Hillman Alcohols. J. Org. Chem. 2016, 12, 2402-2409. e) Kwon, Y.; Jung, J.; Kim, J. H.; Kim, W. J.; Kim, S. Amide Acetal in Palladium-Catalyzed Allylation with Allylic Alcohols under Neutral Conditions. Asian J. Org. Chem. 2017, 6, 520-526. f) Bernhard, Y.; Thomson, B.; Ferey, V.; Sauthier, M. Nickel-Catalyzed $\alpha$-Allylation of Aldehydes and Tandem Aldol Condensation/Allylation Reaction with Allylic Alcohols. Angew. Chem., Int. Ed. 2017, 56, 7460-7464. g) Li, J.; Tan, C.; Mu, X.; Gong, J.; Yang, Z. Synthesis of Substituted Benzoxacycles via a Pd(II)-Catalyzed Intramolecular Arylation Reaction of Allylic Alcohols. Chinese J. Chem. 2017, 35, 562-566. h) Yang, B.; Wang, Z. X. Nickel-Catalyzed Cross-Coupling of Allyl alcohols with Aryl- or Alkenylzinc Reagents. J. Org. Chem. 2017, 82, 4542-4549. i) Fu, M. C.; Shang, R.; Cheng, W. M.; Fu, Y. Efficient Pd-Catalyzed Regio- and Stereoselective Carboxylation of Allylic Alcohols with Formic Acid. Chem. Eur. J. 2017, 23, 8818-8822. j) Tu, H. F.; Zheng, C.; Xu, R. Q.; Liu, X. J.; You, S. L. Iridium-Catalyzed Intermolecular Asymmetric Dearomatization of $\beta$-Naphthols with Allyl Alcohols or Ally Ethers. Angew. Chem., Int. Ed. 2017, 56, 3237-3241; k) Wu, F. P.; Peng, J. B.; Fu, L. Y.; Qi, X.; Wu, X. F. Direct Palladium-Catalyzed Carbonylative Transformation of Allylic Alcohols and Related Derivatives. Org. Lett. 2017, 19, 5474-5477. I) Bouhalleb, G.; Mhasni, O.; Poli, G.; Rezgui, F. Direct Palladium-Catalyzed Allylic Alkylations of Alcohols with Enamines: Synthesis of Homoallyl Ketones. Tetrahedron Lett. 2017, 58, 2525-2529. m) Nazari, S. H.; Bourdeau, J. E.; Talley, M. R.; Valdivia-Berroeta, G. A.; Smith, S. J.; Michaelis, D. J. NickelCatalyzed Suzuki Cross Couplings with Unprotected Allylic Alcohols Enabled by Bidentate $\mathrm{N}$-Heterocyclic Carbene (NHC)/Phosphine Ligands. ACS Catal. 2018, 8, 86-89. n) Wang, G.; Gan, Y.; Liu, Y. Nickel-Catalyzed Direct Coupling of Allylic Alcohols with Organoboron Reagents. Chinese J. Chem. 2018, 36, 916-920. o) Shimizu, A.; Hirata, G.; Onodera, G.; Kimura, M. Direct Allylation of Active Methylene Compounds with Allylic Alcohols by Use of Palladium/PhosphineBorane Catalyst System. Adv. Synth. Catal. 2018, 360, 1954-1960. p) Lauwick, H.; Sun, Y.; Akdas-Kilig, H.; Dérien, S.; Achard, M. J. Access to 3-Oxindoles from Allylic Alcohols and Indoles. Chem. Eur. J. 2018, 24, 7964-7969. q) Hu, X. Q.; Hu, Z.; Trita, A. S.; Zhang, G.; Gooßen, L. J. Carboxylate-Directed C-H Allylation with Allyl Alcohols or Ethers. Chem. Sci. 2018, 9, 5289-5294. r) Jia, X. G.; Guo, P.; Duan, J.; Shu, X. Z. Dual Nickel and Lewis Acid Catalysis for Cross-Electrophile Coupling: the Allylation of Aryl Halides with Allylic Alcohols. Chem. Sci. 2018, 9, 640-645. s) Yan, R.; Wang, Z. X. Rhodium-Catalyzed Alkenyl C-H Activation and Oxidative Coupling with Allylic Alcohols. Asian J. Org. Chem. 2018, 7, 240-247. t) Motokura, K.; Ikeda, M.; Kim, M.; Nakajima, K.; Kawashima, S.; Nambo, M.; Chun, W. J.; Tanaka, S. Silica Support-Enhanced Pd-Catalyzed Allylation Using Allylic Alcohols. ChemCatChem 2018, 10, 4536-4544. u) Ngamnithiporn, A.; Jet- 
te, C. I.; Bachman, S.; Virgil, S. C.; Stoltz, B. M. Nickel-Catalyzed Enantioselective Allylic Alkylation of Lactones and Lactams with Unactivated Allylic Alcohols. Chem. Sci. 2018, 9, 2547-2551. v) Yan, P.; Pan, S.; Hu, J.; Lu, L.; Zeng, X.; Zhong, G. Palladium Catalyzed Controllable Mono- or Di-Allylic Substitution Reaction of Benzothiazolylacetate with Allylic Alcohols. Adv. Synth. Catal. 2019, 361, 13221334. w) Ma, X.; Yu, J.; Han, C.; Zhou, Q.; Ren, M.; Li, L.; Tang, L. Dehydrative Synthesis of Functionalized Skipped Dienes from Stabilized Phosphonium Ylides and Allylic Alcohols in Water. Adv. Synth. Catal. 2019, 361, 1023-1027. x) Haruki, H.; Yasuda, S.; Nagao, K.; Ohmiya, H. Dehydrative Allylation between Aldehydes and Allylic Alcohols through Synergistic $\mathrm{N}$-Heterocyclic Carbene/Palladium Catalysis. Chem. Eur. J. 2019, 25, 724-727.

(17) Asymmetric $\mathrm{C}-\mathrm{N}$ bond formation reactions using allylic alcohols, previous reports are in references 1: a) Zhang, M.; Watanabe, K.; Tsukamoto, M.; Shibuya, R.; Morimoto, H.; Ohshima, T. A Short Scalable Route to (-)- $\alpha$-Kainic Acid Using Pt-Catalyzed Direct Allylic Amination. Chem. Eur. J. 2014, 21, 3937-3941. b) Yan, L.; Xu, J. K.; Huang, C. F.; He, Z. Y.; Xu, Y. N.; Tian, S. K. Kinetic Resolution of Racemic Allylic Alcohols by Catalytic Asymmetric Substitution of the OH Group with Monosubstituted Hydrazines. Chem. Eur. J. 2016, 22, 13041-13045. c) Akkarasamiyo, S.; Sawadjoon, S.; Orthaber, A.; Samec, J. S. M. Tsuji-Trost Reaction of Non-Derivatized Allylic Alcohols. Chem. Eur. J. 2018, 24, 3488-3498.

(18) $\mathrm{C}-\mathrm{N}$ bond formation reactions using allylic alcohols, previous reports are in references 1: a) Kita, Y.; Sakaguchi, H.; Hoshimoto, Y.; Nakauchi, D.; Nakahara, Y.; Carpentier, J. F.; Ogoshi, S.; Mashima, K. Pentacoordinated Carboxylate $\pi$-Allyl Nickel Complexes as Key Intermediates for the Ni-Catalyzed Direct Amination of Allylic Alcohols. Chem. Eur. J. 2015, 21, 14571-14578. b) Kang, K.; Kim, J.; Lee, A.; Kim, W. Y.; Kim, H. Palladium-Catalyzed Dehydrative Cross-Coupling of Allylic Alcohols and $\mathrm{N}$-Heterocycles Promoted by a Bicyclic Bridgehead Phosphoramidite Ligand and an Acid Additive. Org. Lett. 2016, 18, 616-619. c) Li, H.; Neumann, H.; Beller, M. Palladium-Catalyzed Aminocarbonylation of Allylic Alcohols. Chem. Eur. J. 2016, 22, 10050-10056. d) Abidi, A.; Oueslati, Y.; Rezgui, F. E트ㄹㅡㅡ-Mediated Palladium-Catalyzed Direct Allylic Substitution Reactions of MoritaBaylis-Hillman Alcohols with Aromatic Amines. Synth. Commun. 2016 46, 1916-1923. e) Azizi, M. S.; Edder, Y.; Karim, A.; Sauthier, M. Nickel(0)-Catalyzed $N$-Allylation of Amides and $p$ Toluenesulfonamide with Allylic Alcohols under Neat and Neutral Conditions. Eur. J. Org. Chem. 2016, 2016, 3796-3803. f) Emayavaramban, B.; Roy, M.; Sundararaju, B. Iron-Catalyzed Allylic Amination Directly from Allylic Alcohols. Chem. Eur. J. 2016, 22, 3952-3955. g) Hirata, G.; Satomura, H.; Kumagae, H.; Shimizu, A.; Onodera, G.; Kimura, M. Direct Allylic Amination of Allylic Alcohol Catalyzed by Palladium Complex Bearing Phosphine-Borane Ligand. Org. Lett. 2017, 19 6148-6151. h) Jing, J.; Huo, X.; Shen, J.; Fu, J.; Meng, Q.; Zhang, W. Direct Use of Allylic Alcohols and Allylic Amines in PalladiumCatalyzed Allylic Amination. Chem. Commun. 2017, 53, 5151-5154. i) Sweeney, J. B.; Ball, A. K.; Lawrence, P. A.; Sinclair, M. C.; Smith, L. J. A Simple, Broad-Scope Nickel(0) Precatalyst System for the Direct Amination of Allyl Alcohols. Angew. Chem., Int. Ed. 2018, 57, 1020210206. j) Xie, J.; Xue, S.; Escudero-Adán, E. C.; Kleij, A. W. Domino Synthesis of $\alpha, \beta$-Unsaturated $\gamma$-Lactams by Stereoselective Amination of $\alpha$-Tertiary Allylic Alcohols. Angew. Chem., Int. Ed. 2018, 57, 16727-16731. k) Kumar, G. S.; Singh, D.; Kumar, M.; Kapur, M. Palladium-Catalyzed Aerobic Oxidative Coupling of Allylic Alcohols with Anilines in the Synthesis of Nitrogen Heterocycles. J. Org. Chem. 2018, 83, 3941-3951. I) Sakuramoto, T.; Hirao, T.; Tobisu, M.; Moriuchi, T. Oxovanadium (V)-Catalyzed Direct Amination of Allyl Alcohols. ChemCatChem 2019, 11, 1175-1178.

(19) $\mathrm{C}-\mathrm{C}$ bond formation reactions using allylic ethers, previous reports are in references 1: a) Huo, X.; Quan, M.; Yang, G.; Zhao, X.; Liu, D.; Liu, Y.; Zhang, W. Hydrogen-Bond-Activated Palladium-Catalyzed AlIylic Alkylation via Allylic Alkyl Ethers: Challenging Leaving Groups. Org. Lett. 2014, 16, 1570-1573. b) Qi, L.; Ma, E.; Jia, F.; Li, Z. IronCatalyzed allylic Substitution Reactions of Allylic Ethers with Grignard Reagents. Tetrahedron Lett. 2016, 57, 2211-2214. c) Ma, E.; Jiang,
Y.; Chen, Y.; Qi, L.; Yan, X.; Li, Z. Salicylate-Directed C-O Bond Cleavage: Iron-Catalyzed Allylic Substitution with Grignard Reagents. Asian J. Org. Chem. 2018, 7, 914-917. d) Yao, K.; Yuan, Q.; Qu, X.; Liu, Y.; Liu, D.; Zhang, W. Pd-Catalyzed Asymmetric Allylic Substitution Cascade using $\alpha$-(Pyridin-1-yl)-acetamides Formed in situ as Nucleophiles. Chem. Sci. 2019, 10, 1767-1772.

(20) Zhao, X.; Liu, D.; Guo, H.; Liu, Y.; Zhang, W. C-N Bond Cleavage of Allylic Amines via Hydrogen Bond Activation with Alcohol Solvents in Pd-Catalyzed Allylic Alkylation of Carbonyl Compounds. J. Am. Chem. Soc. 2011, 133, 19354-19357

(21) Asymmetric $\mathrm{C}-\mathrm{C}$ bond formation reactions using allylic amines: a) Mukherjee, S.; List, B. Chiral Counteranions in Asymmetric TransitionMetal Catalysis: Highly Enantioselective Pd/Brønsted Acid-Catalyzed Direct $\alpha$-Allylation of Aldehydes. J. Am. Chem. Soc. 2007, 129, 11336-11337. b) Wang, Y.; Xu, Y. N.; Fang, G. S.; Kang, H. J.; Gu, Y.; Tian, S. K. Kinetic Resolution of Primary Allylic Amines via Palladium-Catalyzed Asymmetric Allylic Alkylation of Malononitriles. Org. Biomol. Chem. 2015, 13, 5367-5371. c) Li, M. B.; Wang, Y.; Tian, S. K. Regioselective and Stereospecific Cross-Coupling of Primary Allylic Amines with Boronic Acids and Boronates through PalladiumCatalyzed C-N Bond Cleavage. Angew. Chem., Int. Ed. 2012, 51, 2968-2971. d) Xu, J. K.; Wang, Y.; Gu, Y.; Tian, S. K. PalladiumCatalyzed Stereospecific Allylation of Nitroacetates with Enantioenriched Primary Allylic Amines. Adv. Synth. Catal. 2016, 358, 18541858.

(22) C $-\mathrm{C}$ bond formation reactions using allylic amines: a) Murahashi, S.-I. Makabe, Y. Palladium (0) Catalyzed 3-Aza-Cope Rearrangement of N-allylenamines. Tetrahedron Lett. 1985, 26, 5563-5566. b) Murahashi, S.-I.; Makabe, Y.; Kunita, K. Palladium(0)-Catalyzed Rearrangement of $N$-Allylenamines. Synthesis of $\delta, \varepsilon$-Unsaturated Imines and $\gamma, \delta$-Unsaturated Carbonyl Compounds. J. Org. Chem. 1988, 53, 4489-4495. c) Lowe, M. A.; Ostovar, M.; Ferrini, S.; Chen, C. C.; Lawrence, P. G.; Fontana, F.; Calabrese, A. A.; Aggarwal, V. K. Palladium-Mediated Annulation of Vinyl Aziridines with Michael Acceptors: Stereocontrolled Synthesis of Substituted Pyrrolidines and Its Application in a Formal Synthesis of (-)-a-Kainic Acid. Angew. Chem., Int. Ed. 2011, 50, 6370-6374. d) Dubovyk, I.; Pichugin, D.; Yudin, A. K. Palladium-Catalyzed Ring-Contraction and Ring-Expansion Reactions of Cyclic Allyl Amines. Angew. Chem., Int. Ed. 2011, 50, 59245926. e) Ma, X. T.; Wang, Y.; Dai, R. H.; Liu, C. R.; Tian, S. K. Catalytic Allylation of Stabilized Phosphonium Ylides with Primary Allylic Amines. J. Org. Chem. 2013, 78, 11071-11075. f) Hu, X. Q.; Hu, Z.; Zhang, G.; Sivendran, N.; Gooßen, L. J. Catalytic C-N and C-H Bond Activation:ortho-Allylation of Benzoic Acids with Allyl Amines. Org. Lett. 2018, 20, 4337-4340. g) Yan, R.; Wang, Z. X. Ruthenium-Catalyzed

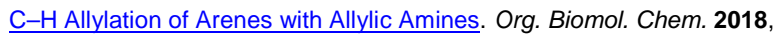
16, 3961-3969.

(23) Asymmetric $\mathrm{C}-\mathrm{N}$ bond formation reactions using allylic amines: a) Trost, B. M.; Fandrick, D. R.; Brodmann, T.; Stiles, D. T. Dynamic Kinetic Asymmetric Allylic Amination and Acyl Migration of Vinyl Aziridines with Imido Carboxylates. Angew. Chem., Int. Ed. 2007, 46, 6123-6125. b) Trost, B. M.; Osipov, M.; Dong, G. PalladiumCatalyzed Dynamic Kinetic Asymmetric Transformations of Vinyl Aziridines with Nitrogen Heterocycles: Rapid Access to Biologically Active Pyrroles and Indoles. J. Am. Chem. Soc. 2010, 132, 1580015807.

(24) $\mathrm{C}-\mathrm{C}$ bond formation reaction via cleavage of allylic $\mathrm{C}-\mathrm{H}$ bond; a) Trost, B. M.; Donckele, E. J.; Thaisrivongs, D. A.; Osipov, M.; Masters, J. T. A New Class of Non- $C_{2}$-Symmetric Ligands for Oxidative and Redox-Neutral Palladium-Catalyzed Asymmetric Allylic Alkylations of 1,3-Diketones. J. Am. Chem. Soc. 2015, 137, 2776-2784. b) Trost, B. M.; Li, X. Pd-Catalyzed Asymmetric Allylic Alkylations via C-H Activation of $N$-allyl Imines with Glycinates. Chem. Sci. 2017, 8, 6815-6821. c) Liu, W.; Ali, S. Z.; Ammann, S. E.; White, M. C. Asymmetric Allylic C-H Alkylation via Palladium(II)/cis-ArSOX Catalysis. J. Am. Chem. Soc. 2018, 140, 10658-10662. d) Tanaka, S.; Ramachandran, G.; Hori, Y.; Kitamura, M. Bisamidine-Cu(I)-catalyzed C-Allylation of 1,3Dicarbonyl Compounds with Simple Cyclic Alkenes Using Di-tert-butyl Peroxide. Chem. Lett. 2018, 47, 1486-1489. e) Reddi, Y.; Tsai, C. C.; 
Avila, C. M.; Toste, F. D.; Sunoj, R. B. Harnessing Noncovalent Interactions in Dual-Catalytic Enantioselective Heck-Matsuda Arylation. J. Am. Chem. Soc. 2019, 141, 998-1009.

(25) Achiral allylation reaction mediated by Ni catalyst; Sweeney, J. B.; Ball, A. K.; Smith, L. J.; Catalytic C-C Bond Formation Using a Simple Nickel Precatalyst System: Base- and Activator-Free Direct CAllylation by Alcohols and Amines. Chem. Eur. J. 2018, 24, 73547357.

(26) For results using other nucleophiles, see Table S4.

(27) $\mathrm{pKa}$ values of $\beta$-diketone, $\beta$-ketoester, $\beta$-ketoamide, and $\beta$-ketonitrile in DMSO. a) Bordwell, F. G.; van der Puy, M.; Vanier, N. R. Carbon Acids. 8. The Trimethylammonio Group as a Model for Assessing the Polar Effects of Electron-Withdrawing Groups. J. Org. Chem. 1976, 41 1883-1885; b) Olmstead, W. N.; Bordwell, F. G. Ion-Pair Association Constants in Dimethyl Sulfoxide J. Org. Chem. 1980, 45, 3299-3305; c) Bordwell, F. G.; Harrelson, Jr. J. A. Acidities and homolytic bond dissociation energies of the $\mathrm{aC}-\mathrm{H}$ bonds in ketones in DMSO. Can. J. Chem. 1990, 68, 1714-1718; d) Bordwell, F. G.; Fried, H. E. Heterocyclic Aromatic Anions with $4 n+2 \pi$-Electrons. J. Org. Chem. 1991, 56, 4218-4223.

(28) Crystal structures of nickel complexes having two phosphine ligands and one olefine: a) Karsch, H. H.; Leithe, A. W.; Reisky, M.; Witt, E. Nickel Complexes with Heterobutadiene Ligands. Organometallics 1999, 18, 90-98. b) Maciejewski, H.; Sydor, A.; Marciniec, B.; Kubicki, M.; Hitchcock, P. B. Intermediates in Nickel(0)-Phosphine Complex Catalyzed Dehydrogenative Silylation of Olefins. Inorg. Chim. Acta 2006, 359, 2989-2997. c) Zhang, X.; Tutkowski, B.; Oliver, A.; Helquist, P.; Wiest, O. Mechanistic Study of the Nickel-Catalyzed $\alpha, \beta$ Coupling of Saturated Ketones. ACS Catal. 2018, 8, 1740-1747.

(29) Dierkes, P.; van Leeuwen, P. W. N. M. The bite angle makes the difference: a practical ligand parameter for diphosphine ligands. J. Chem. Soc., Dalton Trans. 1999, 1519-1529.

(30) Percent buried volumes in the complexes $\mathbf{4 a}$ and $\mathbf{4 b}$ were calculated as $51.1 \% \mathrm{~V}_{\text {bur }}$ for $\mathbf{4 a}$ and $52.8 \% \mathrm{~V}_{\text {bur }}$ for $\mathbf{4 b}$. We considered the nickel as the center of the sphere and two $\mathrm{P}$ for axis definition. The molecular structure of (S)-Tol-MeO-BIPHEP-Ni(cod) complex was optimized by Gaussian 16 package.

(31) a) Falivene, L.; Cao, Z.; Petta, A.; Serra, L.; Poater, A.; Oliva, R.; Scarano, V.; Cavallo, L. Towards the online computer-aided design of catalytic pockets. Nat. Chem. 2019, 11, 872-879. b) Falivene, L.; Credendino, R.; Poater, A.; Petta, A.; Serra, L.; Oliva, R.; Scarano, V.; Cavallo, L. SambVca 2. A Web Tool for Analyzing Catalytic Pockets with Topographic Steric Maps. Organometallics 2016, 35, 2286-2293; Topographic steric maps were described by SambVca2.0. (https://www.molnac.unisa.it/OMtools/ sambvca2.0/). c) Clavier, H.; Nolan, S. P. Percent buried volume for phosphine and $\mathrm{N}$-heterocyclic carbeneligands: steric properties in organometallic chemistry. Chem. Commun. 2010, 46, 841-861.

(32) a) Burés, J. A Simple Graphical Method to Determine the Order in Catalyst. Angew. Chem., Int. Ed., 2016, 55, 2028-2031. b) Burés, J. Variable Time Normalization Analysis: General Graphical Elucidation of Reaction Orders from Concentration Profiles. Angew. Chem., Int. Ed., 2016, 55, 16084-16087.

(33) a) Hoshimoto, Y.; Hayashi, Y.; Suzuki, H.; Ohashi, M.; Ogoshi, S. One-Pot, Single-Step, and Gram-Scale Synthesis of Mononuclear [ $\left(\mathrm{n}^{6}\right.$ - arene) $\mathrm{Ni}(\mathrm{N}$-heterocyclic carbene)] Complexes: Useful Precursors of the $\mathrm{Ni}^{0}-\mathrm{NHC}$ Unit. Organometallics 2014, 33, 1276-1282. b) Bajo, S.; Laidlaw, G.; Kennedy, A. R.; Sproules, S.; Nelson, D. J. Oxidative Addition of Aryl Electrophiles to a Prototypical Nickel(0) Complex: Mechanism and Structure/Reactivity Relationships. Organometallics 2017, 36, 1662-1672.

(34) We also excluded another possible pathway via neutral nickel complexes, TS1neut $^{\text {outer }}$, TS1neut ${ }^{\text {inner }}$, and neutral nickel complex TS1cat ${ }^{\text {inner }}$. All reaction pathways calculated are shown in Figure S6 in the supporting information.

(35) According to the benchmark calculations carried out by the Truhlar's group (Schultz, N. E.; Zhao, Y.; Truhlar, D. G. Benchmarking approximate density functional theory for $s / d$ excitation energies in $3 \mathrm{~d}$ transition, metal cations. J. Comput. Chem. 2008, 29, 185-189; Zhao, Y.; Truhlar, D. G. Density functionals with broad applicability in chemistry. Acc. Chem. Res. 2008, 41, 157-167; Zhao, Y.; González-García, N.; Truhlar, D. G. Benchmark database of barrier heights for heavy atom transfer, nucleophilic substitution, association, and unimolecular reactions and their use to test DFT. J. Phys. Chem. A 2005, 109, 20122018), the absolute error range of the method used in this study can vary from 4 to $5 \mathrm{kcal} \cdot \mathrm{mol}^{-1}$ for calculations of transition states. Since this precision range is commensurate with our calculated energy difference $\left(6.6 \mathrm{kcal}_{\mathrm{mol}}{ }^{-1}\right)$, the real value can be lower and, thus, the actual equilibrium can be established more easily.

(36) Pangborn, A. B.; Giardello, M. A.; Grubbs, R. H.; Rosen, R. K.; Timmers, F. J. Safe and Convenient Procedure for Solvent Purification. Organometallics 1996, 15, 1518-1520.

(37) Frisch, M. J.; Trucks, G. W.; Schlegel, H. B.; Scuseria, G. E.; Robb, M. A.; Cheeseman, J. R.; Scalmani, G.; Barone, V.; Mennucci, B.; Petersson, G. A.; Nakatsuji, H.; Caricato, M.; Li, X.; Hratchian, H. P.; Izmaylov, A. F.; Bloino, J.; Zheng, G.; Sonnenberg, J. L.; Hada, M.; Ehara, M.; Toyota, K.; Fukuda, R.; Hasegawa, J.; Ishida, M.; Nakajima, T.; Honda, Y.; Kitao, O.; Nakai, H.; Vreven, T.; Montgomery, J. A., Jr.; Peralta, J. E.; Ogliaro, F.; Bearpark, M.; Heyd, J. J.; Brothers, E.; Kudin, K. N.; Staroverov, V. N.; Kobayashi, R.; Normand, J.; Raghavachari, K.; Rendell, A.; Burant, J. C.; Iyengar, S. S.; Tomasi, J.; Cossi, M.; Rega, N.; Millam, J. M.; Klene, M.; Knox, J. E.; Cross, J. B.; Bakken, V.; Adamo, C.; Jaramillo, J.; Gomperts, R.; Stratmann, R. E.; Yazyev, O.; Austin, A. J.; Cammi, R.; Pomelli, C.; Ochterski, J. W.; Martin, R. L.; Morokuma, K.; Zakrzewski, V. G.; Voth, G. A.; Salvador, P.; Dannenberg, J. J.; Dapprich, S.; Daniels, A. D.; Farkas, Ö.; Foresman, J. B.; Ortiz, J. V.; Cioslowski, J.; Fox, D. J. Gaussian 09, Revision D.01; Gaussian Inc.: Pittsburgh, PA, 2009.

(38) a) Becke, A. D. Density-functional exchange-energy approximation with correct asymptotic behavior. Phys. Rev. A 1988, 38, 3098-3100; b) Becke, A. D. Density - functional thermochemistry. III. The role of exact exchange. J. Chem. Phys. 1993, 98, 5648-5652.

(39) Marenich, A. V.; Cramer, C. J.; Truhlar, D. G. Universal Solvation Model Based on Solute Electron Density and on a Continuum Model of the Solvent Defined by the Bulk Dielectric Constant and Atomic Surface Tensions. J. Phys. Chem. B, 2009, 113, 6378-6396.

(40) Gonzales, C.; Schlegel, H. B. An improved algorithm for reaction path following. J. Chem. Phys. 1989, 90, 2154-2161. 


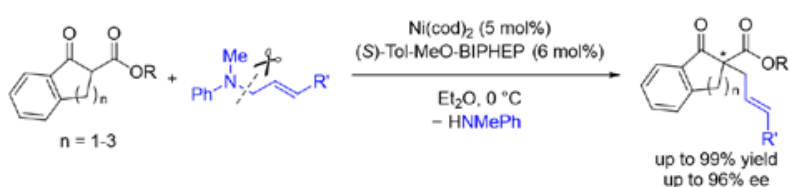

Isolation of intermediate Two Key Transition States (DFT calculations)
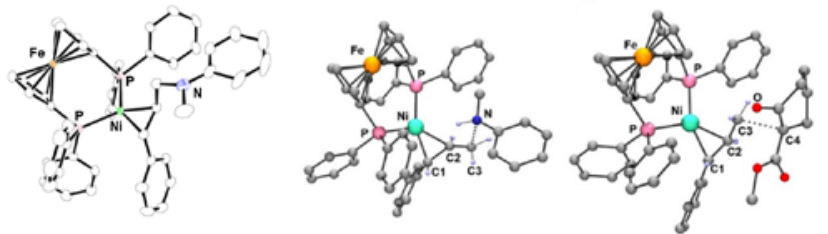